\title{
Trademarks, Consumer Psychology, and the Sophisticated Consumer
}

Glenn L. Christensen

glennc@byu.edu

Eric D. DeRosia

Thomas R. Lee

Follow this and additional works at: https://scholarsarchive.byu.edu/facpub

Part of the Business Administration, Management, and Operations Commons

\section{Original Publication Citation}

Thomas R. Lee, Glenn L. Christensen \& Eric D. DeRosia, Trademarks, Consumer Psychology, and the Sophisticated Consumer, 57 EMORY L.J. 575 (28).

\section{BYU ScholarsArchive Citation}

Christensen, Glenn L.; DeRosia, Eric D.; and Lee, Thomas R., "Trademarks, Consumer Psychology, and the Sophisticated Consumer" (2008). Faculty Publications. 917.

https://scholarsarchive.byu.edu/facpub/917

This Peer-Reviewed Article is brought to you for free and open access by BYU ScholarsArchive. It has been accepted for inclusion in Faculty Publications by an authorized administrator of BYU ScholarsArchive. For more information, please contact ellen_amatangelo@byu.edu. 


\title{
TRADEMARKS, CONSUMER PSYCHOLOGY, AND THE SOPHISTICATED CONSUMER
}

\author{
Thomas R. Lee \\ Glenn L. Christensen ** \\ Eric D. DeRosia***
}

Trademark law rests on an amorphous foundation. The scope of protection afforded to the trademark holder turns on the psychology and behavior of the "ordinary" consumer "under the normally prevalent conditions of the market and giving the attention such purchasers usually give in buying that class of goods." In trademark law, "everything hinges upon whether there is a likelihood of confusion in the mind of an appreciable number of "reasonably prudent' buyers." ${ }^{2}$ Where the ordinary consumer is deemed sufficiently "sophisticated" to discern differences between two competing marks, the law forecloses protection for the senior trademark. ${ }^{3}$

Although the ordinary consumer's mindset is central to trademark law and policy, neither courts nor commentators have made any serious attempt to develop a framework for understanding the conditions that may affect the attention that can be expected to be given to a particular purchase. Some of the classic judicial descriptions cast the ordinary consumer as "ignorant . . . unthinking and . . . credulous" or "hasty, heedless and easily deceived." other cases, the courts have bristled at the "claimed asininity" of the buying public, ${ }^{6}$ suggesting instead that the average buyer is "neither savant nor dolt,"

* Professor of Law, Brigham Young University.

** Assistant Professor, Marriott School of Management, Brigham Young University.

*** Assistant Professor, Marriott School of Management, Brigham Young University.

Thanks to Gregory Phillips, Scott Ryther, Rebecca Tushnet, Barton Beebe, Graeme Dinwoodie, Mark Lemley, Craig Dallon, James Rasband, and Brett Scharffs for their comments on an earlier draft, and to Kelley Marsden, Joseph Benson, and Scott Cowley for their research assistance. The authors also gratefully acknowledge the generous support of research grants from the Marriott School of Business at Brigham Young University.

1 W.W.W. Pharmaceutical Co. v. Gillette Co., 984 F.2d 567, 575 (2d Cir. 1993).

2 J. Thomas MCCARThy, MCCARThy on Trademarks AND Unfair COMPETITION § 23:91 (4th ed. 2007).

3 Id.

4 Florence Mfg. Co. v. J.C. Dowd \& Co., 178 F. 73, 75 (2d Cir. 1910).

5 Stix Prods., Inc. v. United Merchs. \& Mfrs., Inc., 295 F. Supp. 479, 494 (S.D.N.Y. 1968).

6 Pocket Books, Inc. v. Dell Publ'g Co., 268 N.Y.S.2d 46, 47 (Sup. Ct. 1966). 
but is one who "lacks special competency with reference to the matter at hand but has and exercises a normal measure of the layman's common sense and judgment." ${ }^{, 7}$ For the most part, however, the debate is a vacuous war of words, uninformed by any careful theoretical modeling of consumer psychology or empirical study of consumer behavior.

The academic literature is marked by a similarly empty rift. On one hand, so-called "apologist" trademark commentary paints a picture of the consumer as the "fool"- one highly susceptible to even the slightest suggestion of a connection between two trademarks. ${ }^{8}$ So-called "restrictionist" commentary quarrels with the "conception of a consumerate of 'presumptive idiots' who are "apparently befuddled by nearly everything."" 9 Scholars on the restrictionist side of the divide see the consumer as an informed "sovereign" who is "actually habituated to ambiguity," such that "the degree of confusion [she is] actually likely to suffer is less than might otherwise be thought."

This fundamental disagreement is at the heart of a core theoretical divide in the trademark commentary. As Barton Beebe has noted,

The commentator proceeds from an initial assumption about the degree to which consumers act or are acted upon, about the degree to which they are creative subjects or the created objects of the trademark system .... The apologist commentator traditionally assumes that consumers act, the restrictionist, that consumers are

7 United States v. 88 Cases, More or Less, Containing Bireley’s Orange Beverage, 187 F.2d 967, 971 (3d Cir. 1951) (rejecting "the ignorant, the unthinking, and the credulous" standard as an "extraordinary standard").

8 See Barton Beebe, Search and Persuasion in Trademark Law, 103 Mich. L. Rev. 2020, 2042 (2005) (employing this terminology to describe the disagreement among trademark commentators and asserting that "apologists" argue "that the average consumer possesses a low degree of search sophistication") (citing William M. Landes \& Richard A. Posner, Trademark Law: An Economic Perspective, 30 J.L. \& Econ. 265, 284 (1987)).

9 Id. at 2041 (quoting Robert J. Denicola, Institutional Publicity Rights: An Analysis of the Merchandising of Famous Trade Symbols, 62 N.C. L. REV. 603, 608-09 (1984)); see also Jessica Litman, Breakfast with Batman: The Public Interest in the Advertising Age, 108 YALE L.J. 1717, 1722 (1999) (noting that trademark owners extract exceedingly broad protection when they convince the court to "protect fictional consumers who ... [are] ... gullible, careless, and easily deceived").

10 Rochelle Cooper Dreyfuss, We Are Symbols and Inhabit Symbols, So Should We Be Paying Rent? Deconstructing the Lanham Act and Rights of Publicity, 20 COLUM.-VLA J.L. \& ARTS 123, 154 (1995); see also Ann Bartow, Likelihood of Confusion, 41 SAN DIEGo L. REV. 721, 723 (2004) (questioning the characterization in the case law of consumers as "astoundingly naïve, stunningly gullible, and frankly stupid"); Stephen L. Carter, The Trouble with Trademark, 99 YALE L.J. 759, 789 (1990) ("Consumers may be more sophisticated than the Landes and Posner model assumes."). 
acted upon. From these premises follow calls for more or less or at least different kinds of paternalism. ${ }^{11}$

Although scholars offer strikingly different portrayals of the reasonably prudent purchaser, neither camp has attempted a comprehensive examination of the theoretical or empirical bases for their positions. Even Beebe, who makes a significant contribution in identifying some internal conflicts in each side's positions, openly declines to "take sides in this debate," 12 while acknowledging that "trademark law lacks a well-developed theory of the consumer, and, specifically, of consumer sophistication."13

This Article attempts to fill that void. We take seriously the oft-repeatedbut seldom heeded-view that the fields of "cognitive and consumer psychology" have "much to offer those interested in trademark law."14 Borrowing from scholarly literature in marketing and consumer psychology, we develop an extensive model of consumer sophistication. In the sections below, we first present a general summary of the relevant case law and then introduce the consumer behavior model that will serve as the core of our analysis. The model identifies two general antecedents to the exercise of consumer care (or "cognition," as it is phrased in the literature) by a sophisticated consumer: a sufficient level of "motivation" for care and an adequate "ability" to be careful. ${ }^{15}$

After developing the motivation and ability elements in some detail, we employ the model to analyze a strand of case law that is at the heart of the

11 Beebe, supra note 8, at 2069.

$12 I d$. at 2025. This is not to denigrate Beebe's contribution. His essay draws an important distinction between "persuasion sophistication" and "search sophistication," and "expose[s] and analyze[s] the inconsistent uses that have been made of the sovereign and the fool in trademark advocacy and adjudication." Id.

13 Id. See Bartow, supra note 10, at 772 (lamenting the judicial substitution of intuition and stereotype for "specific and persuasive evidence about consumer behavior"); see also Barton Beebe, An Empirical Study of the Multifactor Tests for Trademark Infringement, 94 CAL. L. REV. 1581, 1581 (2006) (asserting that the various "multifactor tests for the likelihood of confusion have long played a role of central importance in American trademark litigation, yet they have received little academic attention and no empirical analysis").

14 Jacob Jacoby, The Psychological Foundations of Trademark Law: Secondary Meaning, Genericism, Fame, Confusion and Dilution, 91 TRADEMARK REP. 1013, 1014 (2001); see also id. at 1068 (asserting that trademark practitioners and judges should no longer "rely on common sense or speculation regarding how the consumer's mind operates," and that "new findings regarding cognitive processes" can provide a "scientific foundation[]" for the law to replace "unreliable intuition" and "junk science"); Jerre B. Swann, An Interdisciplinary Approach to Brand Strength, 96 TRADEMARK REP. 943, 945 (2006) (asserting that recent advances in "marketing and consumer psychology . . . possess untapped potential" in facilitating "more predictable, accurate and consumer-beneficial outcomes in trademark conflicts").

15 See infra Part II. 
broader debate about the consumer mindset - cases that identify circumstances where the consumer is expected to be more, or less, "sophisticated." The informed, rigorous view of the consumer that emerges is much more nuanced and complex than that of either fool or sovereign. We offer a positive framework for understanding the basic strands of the judicial conceptions of consumer sophistication and interject normative criticism in cases where we find fault with the jurisprudence. Lastly, we employ the model to take a broader look at the relevance (and relative significance) of consumer sophistication in trademark infringement cases.

Our methodology offers insights that can inform - and transform - a broad range of issues in a body of law that can no longer afford to ignore the field of consumer psychology. By moving beyond stereotypes and rhetorical flourishes about the validity vel non of the portrayal of the consumer as the "presumptive idiot," our model opens analytical doors that account for the realities of consumer behavior and helps to resolve many of the conflicts and inconsistencies in trademark law.

\section{THE LIKELIHOOD OF CONFUSION AND THE REASONABLY PRUDENT CONSUMER}

The legal touchstone of trademark infringement is a showing of a likelihood of consumer confusion. ${ }^{16}$ In evaluating the likelihood of confusion, the standard focuses on the "ordinary" or "reasonably prudent" consumer. ${ }^{17}$ As noted above, the courts have expressed a range of different views as to the mindset of this "ordinary" or "reasonably prudent" consumer. ${ }^{18}$ To some degree, the cases leave room for the impression that courts may simply be "adjusting their finding of whether the relevant consumer population is

16 See 15 U.S.C. § 1114(1) (2006) (establishing that a federally registered mark is infringed where the defendant's use is "likely to cause confusion, or to cause mistake, or to deceive").

17 See Savin Corp. v. Savin Group, 391 F.3d 439, 461 (2d Cir. 2004) ("[T]he pertinent question is whether 'numerous ordinary prudent purchasers' would likely 'be misled or confused as to the source of the product in question because of the entrance in the marketplace of [Defendants'] mark."'); Dreamwerks Prod. Group, Inc. v. SKG Studio, 142 F.3d 1127, 1129 (9th Cir. 1998) ("The test for likelihood of confusion is whether a reasonably prudent consumer in the marketplace is likely to be confused as to the origin of the good or service bearing one of the marks."); see also MCCARTHY, supra note 2, § 23:93 (asserting and citing extensive cases for the proposition that "everything hinges upon whether there is a likelihood of confusion in the mind of an appreciable number of 'reasonably prudent' buyers").

18 See sources cited supra note 17. 
sophisticated or unsophisticated to conform to the result they wish to achieve." 19

Despite this cynical characterization, the courts have long evaluated the likelihood of confusion under a series of circumstantial factors. The seminal federal case under the Lanham Act is Polaroid Corp. v. Polarad Electronics Corp. ${ }^{20}{ }^{20}$ which identified the following eight factors relevant to the likelihood of confusion:

[T] he strength of [the plaintiff's] mark, the degree of similarity between the two marks, the [competitive] proximity of the products [or services], the likelihood that [the plaintiff] will bridge the gap [between two markets], [the existence of] actual confusion, and the reciprocal of defendant's good faith in adopting its own mark, the quality of [the] defendant's product, and the sophistication of the buyers. $^{21}$

Since then, federal courts have offered some variations on these themes, but courts continue to focus primarily on the areas identified by the Second Circuit. $^{22}$

The eighth factor, referred to alternatively as the "consumer's degree of care," 23 or "consumer sophistication," 24 encompasses several considerations that are thought by the courts to affect the attention consumers may pay to their purchases. Under this factor, the courts generally hold that if a consumer can be expected to exercise a high degree of care, she will be less likely to be confused by any connection between a senior and junior trademark. ${ }^{25} \mathrm{~A}$

19 Beebe, supra note 8, at 2040; see also id. at $\mathrm{n} .85$ ("[A] cynic would say that . . . when the court wants to find no infringement, it says that the average buyer is cautious and careful . . [b]ut if the judge thinks there is infringement, the judge sets the standard lower and says the average buyer is gullible and not so discerning.") (quoting MCCARTHY, supra note 2, § 23:92).

20287 F.2d 492 (2d Cir. 1961).

21 Id. at 495.

22 See MCCARTHY, supra note 2, at $\$ 23: 19$ (comparing the Polaroid factors to those applied in other circuits and tracing the development of the test from factors identified in the first Restatement of Torts and Restatement (Third) of Unfair Competition). Of the eight Polaroid factors, the seventh (quality of the defendant's product) is the one rogue factor that is not ordinarily adopted in other circuits. See Beebe, supra note 13, at 1644 (noting that this factor is "considered only by the Second and D.C. Circuits"). As Barton Beebe has noted, the various circuits do differ, to some degree, in the nature and wording of the factors they identify and, more importantly, in the weight they appear to give them. See id. at 1587-91 (identifying the points of convergence among the federal circuit courts); $i d$. at 1621-22 (noting some of the variations in the courts' "propensity to stampede the factors").

23 E.g., Sally Beauty Co. v. Beautyco, Inc., 304 F.3d 964, 975 (10th Cir. 2002).

24 E.g., Bristol-Myers Squibb Co. v. McNeil-P.P.C., Inc., 973 F.2d 1033, 1047 (2d Cir. 1992).

25 E.g., Sally Beauty Co., 304 F.3d at 975. 
sophisticated consumer is expected to act not on "impulse," but on the basis of "a careful consideration of the reliability and dependability of the manufacturer and seller of the product." ${ }^{26}$ In other words, a sophisticated consumer is one who is apt to spend more time, attention, or care in making a purchasing decision - and who is thus deemed less likely to be confused as to the source or sponsorship of the trademarked products she buys. ${ }^{27}$ Unsophisticated consumers, by contrast, are "the ignorant, the unthinking[,] and the credulous, who, in making purchases, do not stop to analyze, but are governed by appearance and general impressions." ${ }^{28}$ The prototypical unsophisticated consumer is the man walking the supermarket aisle who "undergo[es] . . . an experience not unlike that of hypnosis," 29 in which purchases are made impulsively and thoughtlessly.

A key threshold question in the case law is how to distinguish the careful and sophisticated consumer from the unthinking and credulous one. Although the courts have not attempted to articulate any comprehensive theoretical framework for assessing consumer propensities toward care, a few consistent themes have emerged in the case law. ${ }^{30}$ The principal strands of analysis in the case law, which are elaborated and evaluated in some detail below, include the assertion that consumer care or sophistication correlates positively with price, ${ }^{31}$ length and complexity of the purchase transaction; ${ }^{32}$ infrequency of purchase; ${ }^{33}$

26 Astra Pharm. Prods., Inc. v. Beckman Instruments, Inc., 718 F.2d 1201, 1206 (1st Cir. 1983).

27 Search sophistication, as formulated by Barton Beebe, "refers to the consumer's capacity to distinguish between similar trademark uses (i.e., to avoid identity confusion), and furthermore, to recognize that such uses designate different sources (i.e., to avoid inferential confusion)." Beebe, supra note 8, at 2035. This is the "sophistication" the law is generally concerned with as a factor relevant to the likelihood of confusion; it is distinct from "persuasion sophistication," a concept Beebe describes as referring "to a consumer's ability to resist commercial persuasion attempts" - to "cope' with marketplace persuasion" aimed at "delud[ing]" the consumer into purchasing a product or service on the basis of the "selling power" or "differential distinctiveness" of a trademark. Id. at 2047-50.

28 Florence Mfg. Co. v. J.C. Dowd \& Co. 178 F. 73, 75 (2d Cir. 1910).

29 Pikle-Rite Co. v. Chi. Pickle Co., 171 F. Supp. 671, 676 (N.D. Ill. 1959).

30 Trademark law treatises provide a general overview of the case law addressing this factor, but not any comprehensive theoretical analysis. See Rudolf CAllmann, Callmann on Unfair Competition, TRADEMARKS AND MONOPOLIES $\$ 21: 10$ (Louis Altman ed., 2003) (stating that the degree of consumer care "will differ according to the "character of the article, the use to which it is put, the kind of people who ask for it, and the manner in which it is ordered"'); JEROME GILSON \& ANNE GILSON LaLONDE, TradEMARK PROTECTION AND PRACTICE $\S 5.08$ (2004) (asserting that "the courts . . . classify purchasers into two types, ordinary purchasers and discriminating or sophisticated purchasers," with the former having "no special training or experience," and the latter having either "special training" or "purchas[ing] costly products"); MCCARTHY, supra note 2, at $\S$ 23:95-23:102 (identifying price, class of purchasers, and other factors relevant to the degree of consumer sophistication).

31 See infra text accompanying notes 139-81.

32 See infra text accompanying notes 183-216. 
education, age, gender, and income $;{ }^{34}$ and the notion that professional buyers, ${ }^{35}$ avid hobbyists, ${ }^{36}$ and (sometimes) women ${ }^{37}$ are more sophisticated.

As explained in further detail below, the case law elaborating these considerations is based on an ad hoc, impressionistic conception of sophistication; the courts have never articulated anything approaching a rigorous, theoretical understanding of consumer care. Yet the perceived degree of sophistication can often be the factor that dictates the degree of protection afforded by law to a trademark holder. Some courts have gone so far as to suggest that a high degree of consumer sophistication in a target market may trump all other factors, virtually eliminating the likelihood of consumer confusion in the case of a professional or highly sophisticated buyer. $^{38}$ Other courts are much more measured in their assessment of the relative significance of this factor, suggesting that its "import" is "small indeed" (at least in cases where the junior and senior trademarks are "identical"). ${ }^{39}$

In assessing the significance of consumer care or sophistication, at least one court has suggested a distinction between source confusion and confusion as to

33 See infra text accompanying notes 217-20.

34 See infra text accompanying notes 258-318.

35 See infra text accompanying notes $222-56$.

36 See id.

37 See infra text accompanying notes 319-30.

38 Sara Lee Corp. v. Kayser-Roth Corp., 81 F.3d 455, 467 (4th Cir. 1996) (holding that the "relative sophistication of the market may trump the presence or absence of any other factor"); see also CALLMANN, supra note 30, at $\$ 21: 12$ (stating that a professional or sophisticated buyer's "detailed knowledge of the product and careful examination with respect to its technical requirements are factors of greater significance than the trademarks used").

39 Kiki Undies Corp. v. Promenade Hosiery Mills, Inc., 411 F.2d 1097, 1101 (2d Cir. 1969); see also Habitat Design Holdings Ltd. v. Habitat, Inc., 436 F. Supp. 327, 332 (S.D.N.Y. 1977) (stating that "[t]he Second Circuit has noted that the importance of this criterion is minimal where the marks in question are identical"). As to the empirical question of whether (and to what extent) the sophistication factor actually does affect the outcomes of the cases, Professor Beebe has concluded that this is the only "non-core" factor that correlates significantly with judicial outcomes. Beebe, supra note 13, at 1612, 1642-43 (identifying as "noncore" factors "purchaser sophistication, similarity of advertising/marketing, similarity of sales facilities, and likelihood of bridging the gap"). Specifically, Beebe concludes that a "finding that the consumer sophistication factor disfavors a likelihood of confusion correlates fairly strongly with an overall finding of no likelihood of confusion," id. at 1612, but that "the Second Circuit is significantly less likely than other circuits to find that the consumer sophistication factor disfavors a likelihood of confusion," id. at 1643. Beebe's study confirms the practical significance of this factor, while also indicating that its significance may vary by circuit. His data, however, say little about whether the sophistication factor should count in the likelihood of confusion inquiry, or, importantly, how its significance may vary depending on the relative strength of the parties' proof on other factors. Our analysis does not offer any empirical answer to this important question, but we do offer some theoretical analysis infra Part IV.B. 
sponsorship. In King of the Mountain Sports, Inc. v. Chrysler Corp., ${ }^{40}$ the Tenth Circuit asserted that consumer care "rarely reduces the risk of sponsorship confusion," given that "[t]he care with which consumers select a product does not impact the association they may make regarding the sponsorship of an event." 41 The Sixth Circuit has staked out a similar position, holding that consumer care is of "minimal" significance in dispelling the likelihood of confusion as to affiliation or sponsorship. ${ }^{42}$

Several courts have also called into question the significance of the consumer sophistication factor in cases involving actionable "initial interest confusion." I3 In Kopman A.S. v. Park Structures, Inc., for example, the Northern District of New York acknowledged that consumers of expensive playground equipment are "relatively sophisticated," but held that such "sophistication cannot protect [a junior trademark user] against initial confusion by consumers." 44 Thus, although sophisticated consumers are less likely to be confused at the point of sale, the court concluded that sophistication does not obviate the possibility that they may "mistakenly" find a "connection" with the senior trademark holder and "develop an interest . . . that [they] would not otherwise have had." 45 The District of New Jersey reached a similar conclusion in a case involving sophisticated consumers of high-end security systems: "Because actual sales to the wrong party are not necessary for a finding of a likelihood of initial interest confusion," the court

$40 \quad 185$ F.3d 1084 (10th Cir. 1999).

41 Id. at 1092.

42 Therma-Scan, Inc. v. Thermoscan, Inc., 295 F.3d 623, 638 (6th Cir. 2002) (citing Daddy's Junky Music Stores v. Big Daddy's Music Ctr., 109 F.3d 275, 285-86 (6th Cir. 1997)).

43 See Promatek Indus., Ltd. v. Equitrac Corp., 300 F.3d 808, 812 (7th Cir. 2002) (finding that use of a competitor's trademark in internet metatag is likely to cause confusion even among sophisticated consumers and explaining that " $[\mathrm{t}]$ he degree of care exercised by consumers could lead to initial interest confusion . . . which is actionable under the Lanham Act"); SecuraComm Consulting, Inc. v. SecuraCom Inc., 984 F. Supp. 286, 299 (D.N.J. 1997) (holding that initial interest confusion of customers of large scale security systems "defeats the sophisticated purchaser defense"); Kopman A.S. v. Park Structures, Inc., 890 F. Supp. 1167, 1180 (N.D.N.Y. 1995) (finding that sophistication of consumers of expensive playground equipment could not avoid likelihood of initial interest confusion). For an extensive (albeit dated) review of the cases, see generally Charles E. Bruzga, Sophisticated Purchaser Defense Avoided Where Pre-Sale Confusion is Harmful-A Brief Note, 78 TRADEMARK REP. 659 (1988).

44 Kopman A.S., 890 F. Supp. at 1180; see id. (adopting defendant's argument that even sophisticated consumers may "mistakenly" find a "connection" with the senior user and "develop an interest ... that [they] would not otherwise have had").

45 Id. 
concluded that "such confusion typically defeats the sophisticated purchaser defense." 46

\section{A CONSUMER BEHAVIOR MODEL OF "SOPHISTICATION": MOTIVATION AND ABILITY AS FACTORS INFLUENCING COGNITIVE EFFORT}

The legal touchstone of trademark infringement boils down to a fundamental matter of consumer psychology. ${ }^{47}$ As such, this legal standard should be shaped by a careful, informed analysis of consumer behavior, not by stereotypes and generalizations about the informed "sovereign" or complete "fool." Thus, a careful investigation of the literature in this field is warranted.

Firms often attempt to differentiate their products from the similar offerings of competitors. ${ }^{48}$ For example, a firm selling gasoline to consumers may add proprietary detergents and performance enhancements to the gasoline in an attempt to differentiate it from other gasolines. Typically, a firm attempting to differentiate its product will "brand" the product with a trademark. When a consumer is faced with a variety of differentiated products in a marketplace, the consumer will try to discern which products would suit her needs better than others. If the consumer finds a familiar brand in the marketplace, the consumer can identify the source of the product and infer the product's attributes and quality much more quickly than if the consumer laboriously investigates the product to determine its attributes and quality. ${ }^{49}$ For example, a motorist seeking gasoline need not do an in-depth analysis of the quality of a gasoline if it is sold under a brand name the consumer knows and respects.

Before the consumer can use the brand as a shortcut for judging the attributes and quality of a product encountered in the marketplace, she must first identify the product's brand. That is to say, the consumer must ascertain the identity of the source of the product (a judgment we refer to hereafter as the

46 SecuraComm Consulting, Inc., 984 F. Supp. at 299 (finding a likelihood of confusion in the junior's use of the SECURACOM mark in competition with plaintiff's SECURACOMM mark).

47 See Mishawaka v. S.S. Kresge, 316 U.S. 203, 205 (1942) ("The protection of trade-marks is the law's recognition of the psychological function of symbols."); RICHARD L. KIRKPATRICK, LIKELIHOOD OF CONFUSION IN TRADEMARK LAW, at $\mathrm{xx}$ (2005) (asserting that "the question of trademark infringement is primarily one of the psychology—cognitive and behavioral—of consumers").

48 See Byron Sharp \& John Dawes, What Is Differentiation and How Does It Work?, 17 J. MARKETING MGMT. 739, 739 (2001) ("Differentiation is an old concept and one that is very basic to modern views of markets and marketing ....").

49 Jacoby, supra note 14 , at 1025. 
"source-identification judgment"). ${ }^{50}$ The role of brands as shortcuts for evaluating quality when products are differentiated suggests that consumers will not always perform source-identification judgments. If the consumer believes competing products are undifferentiated, the brand's identity does not add useful information to the consumer's decision, so she is unlikely to perform the source-identification judgment. For example, a consumer who believes that "all ketchup is the same" is unlikely to bother making a sourceidentification judgment when purchasing ketchup. Furthermore, if the consumer believes that product quality can be fully and easily judged, a shortcut for product evaluation is not useful to the consumer, so she is unlikely to perform the source-identification judgment. For example, a consumer purchasing meat may consider USDA grading to be a sufficient indicator that the meat is safe to consume and accurately labeled, making brand irrelevant.

Arguably, brand name is relevant for the vast majority of consumer purchases. Even products that were once seen as undifferentiated (e.g., gasoline, ketchup, coffee, pickles, bath soap, and water) have been differentiated and branded. ${ }^{51}$ Furthermore, in the absence of a certification mark (e.g., USDA grading for meats, Underwriters Laboratories for portable electronic tools, U.S. Coast Guard for life jackets), consumers often find it difficult to fully evaluate product quality without thorough physical inspection, purchase, and consumption. Because brands are so often relevant to consumer purchases, consumers typically perform a source-identification judgment when they consider products. 52

50 Under a longstanding rule of trademark law, the consumer's "identification" of the source need not extend to an awareness of the actual name of the manufacturer or distributor of the products in question. See 15 U.S.C. $§ 1127$ (2006) (defining a "trademark" as "any word, name, symbol, or device, or any combination thereof-(1) used by a person; or (2) which a person has a bona fide intention to use in commerce and applies to register on the principal register established by this chapter, to identify and distinguish his or her goods, including a unique product, from those manufactured or sold by others and to indicate the source of the goods, even if that source is unknown") (emphasis added). Thus, when we speak of the source-identification judgment, we refer to the trademark law concept of the consumer concluding that products bearing the same trademark come from a common-even if anonymous-source. See MCCARTHY, supra note 2, § 3:7 ("However, the 'identification' function of marks does not mean that the consumer must know the identity of the manufacturer or distributor of the goods. Seeing the same mark on goods merely identifies to the buyer the fact that all such goods come from a common, even though anonymous, source.").

51 Kevin Lane Keller, Strategic Brand Management: Building, Measuring, and Managing BRAND EQUITY 11 (Prentice Hall 2003) (1998).

52 As Jack Jacoby has explained, "brand names serve as information "chunks," in that they "represent core nodes in memory around which other 'associated' information is connected and organized." Jacoby, supra note 14, at 1024 . Thus, "[g]iven only a familiar brand name, a host of relevant and important information can be efficiently called into consciousness." Id. at 1024-25. 
This is not to suggest that consumers always perform the sourceidentification judgment thoroughly and vigilantly. ${ }^{53}$ According to the theories developed in the consumer behavior literature, a consumer attempting to avoid source confusion by making a source-identification judgment must perform a series of steps. First, the consumer must gather product information that she considers of potential relevance to the source-identification judgment. ${ }^{54}$ Such information might include the trademark itself, trade dress, and the price at which the product is being offered. Second, the consumer must comprehend the information - that is, consider the information to determine its meaning. ${ }^{55}$ Whereas some types of information (such as brief and simple written descriptions) are easily comprehended by most consumers, others (such as numeric $^{56}$ and technical ${ }^{57}$ data) are more difficult for most consumers to comprehend. Third, the consumer must identify the implications of the environmental information and integrate the implications to form the sourceidentification judgment. $^{58}$ To perform the source-identification judgment thoroughly and vigilantly, the consumer will form an initial hypothesis (i.e., an initial judgment) concerning the source of the product and then will consider further information in an attempt to validate the initial hypothesis. If the initial hypothesis is not supported by the new information, the process is repeated until the consumer forms a source-identification in which she is sufficiently confident.

Each of the three steps of the source-identification judgment is a mental or cognitive process. That is, each step takes place in the mind of the consumer. One of the main tenets of the consumer psychology literature is that such

53 Nor do we mean to imply that source-identification will be relevant to every consumer. As explained infra Part IV, not every consumer who is equally motivated to engage in effortful cognition can be expected to direct her cognitive resources at the source-identification judgment. Thus, although we adopt the simplifying assumption here that brand names will be relevant to most consumer purchases, we relax that assumption in our broader critique of the law infra Part IV.

54 See Keller, supra note 51, at 9 (proposing brand identification within consumption choice situations constitutes a source-identity judgment); see also Joel B. Cohen \& Kunal Basu, Alternative Models of Categorization: Toward a Contingent Processing Framework, 13 J. ConsuMER RES. 455, 455 (1987) (proposing that brand identification is a categorization judgment, which requires information search about the product at hand).

55 See James R. Bettman, An Information Processing Theory of CONSUMER Choice 29 (1979).

56 Richard F. Yalch \& Rebecca Elmore-Yalch, The Effect of Numbers on the Route to Persuasion, $11 \mathrm{~J}$. CONSUMER RES. 522, 523 (1984).

57 Rolph E. Anderson \& Marvin A. Jolson, Technical Wording in Advertising: Implications for Market Segmentation, 44 J. MARKETING 57, 59-61 (1980).

58 Cohen \& Basu, supra note 54, at 456. 
mental processes require cognitive effort. ${ }^{59}$ Just as physical activity (e.g., climbing stairs) requires physical effort, so mental activity (e.g., searching the environment for information) requires cognitive effort.

Therefore, a consumer can make the source-identification judgment in a thorough and vigilant manner only by expending ample cognitive effort. If she fails to devote sufficient cognitive effort to the source-identification task, it can be expected that she will gather inadequate environmental information, will not attempt to comprehend information that is difficult to comprehend, and will perform the source-identification judgment in a haphazard and offhand way.

Presumably, if a consumer performs the source-identification judgment thoroughly and vigilantly, she is unlikely to suffer source confusion. ${ }^{60}$ However, if she performs the judgment in a haphazard and thoughtless manner, she may not consider the differences between the junior and senior trademarks. As a result, she will be vulnerable to source confusion. ${ }^{61}$ Therefore, one determinant of an individual consumer's likelihood of confusion is the extent to which she expends cognitive effort while making the source-identification judgment.

Fortunately, consumer psychology researchers have given a great deal of research attention to identifying the antecedents of an individual consumer's exertion of cognitive effort. The first broad category of antecedents relates to the individual's motivation to expend cognitive effort. Just as people are typically reluctant to exert physical effort (e.g., people using escalators instead of climbing stairs) but will do so if they are sufficiently motivated, so people will exert cognitive effort only if they are sufficiently motivated. In effect, consumers act as cognitive misers ${ }^{62}$ who exert cognitive effort only when they

59 Yalch \& Elmore-Yalch, supra note 56, at 526; see also Ellen C. Garbarino \& Julie A. Edell, Cognitive Effort, Affect, and Choice, 24 J. CONSUMER RES. 147, 147-48 (1997) (discussing two different studies examining the relationship between consumer psychology and cognitive effort).

60 This is not to suggest that a consumer who performs the source-identification judgment thoroughly and vigilantly cannot be confused. If the junior and senior trademarks are identical, not even a thorough and vigilant inspection by the consumer will prevent source confusion. Furthermore, recent research findings suggest that if two trademarks have the same semantic meaning, consumers who exert a high degree of care may be more confused than consumers who exert a low degree of care. See Daniel J. Howard et al., The Effects of Brand Name Similarity on Brand Source Confusion: Implications for Trademark Infringement, $19 \mathrm{~J}$. PuB. POL'y \& MARKETING 250, 261 (2000).

61 Jean-Noel Kapferer, Brand Confusion: Empirical Study of a Legal Concept, 12 PsyCHOL. \& MARKETING 551, 554 (1995).

62 See Michael J. Houston et al., Picture-Word Consistency and the Elaborative Processing of Advertisements, 24 J. MARKETING RES. 359, 360 (1987) (showing the role of elaborative processing during advertising exposure); see also Alice H. Eagly \& Shelly Chaiken, Attitude Structure and Function, in 1 THE 
have sufficient incentive to do so. ${ }^{63}$ The second broad category of antecedents is the individual's ability to exert cognitive effort. ${ }^{64}$ Just as people may be inhibited in their ability to perform a physical task (e.g., the stairs are particularly steep or the climber has an arthritic knee), so customers can be restricted in their ability to exert cognitive effort as they perform the judgment at hand. Motivation and ability are each necessary but insufficient conditions for an individual to exert cognitive effort. That is, if either motivation or ability is lacking, the individual will exert little cognitive effort while performing a judgment task.

Thus, consumer behavior literature suggests that if a consumer is to perform the source-identification judgment in a meticulous and vigilant manner, she must be sufficiently motivated and able to exert the cognitive effort necessary to perform such a judgment. ${ }^{65}$ In contrast, if an individual lacks either motivation or ability to expend cognitive effort while making the source-identification judgment, she will perform the task in a haphazard and offhand manner, resulting in an increased likelihood of confusion.

Viewed through this theoretical lens, the legal concept of the "degree of consumer care" considered by the courts is similar to the notion described in the consumer behavior literature as the level of exerted cognitive effort. The courts have generally held that if consumers exercise a low degree of care, likelihood of confusion in the marketplace will be increased. ${ }^{66}$ Consumer psychology theory supports the same prediction: If an individual consumer

Handbook OF Social Psychology 269, 292 (Daniel Todd Gilbert et al. eds., 4th ed. 1993) (describing the role of selective attention and perception processes in allocation of limited cognitive resources to salient environmental stimuli); James M. Olson \& Mark P. Zanna, Attitudes and Attitude Change, 44 AnN. Rev. PSYCHOL. 117, 135-36 (1993) (discussing research confirming that consumers engage in the minimum amount of deliberation necessary to provide themselves with sufficient judgmental confidence when making consumption choices).

63 A pejorative reading (i.e., consumers are cognitively lazy and therefore corrupt and deficient) is unnecessary. By expending physical effort only when motivated to do so, humans conserve energy and thereby hold in reserve the energy to act when necessary. An individual who continually expends maximum physical effort at every possible opportunity would expend mostly unnecessary effort and would probably be unable to survive. The same can be said for cognitive effort; if the many judgments an individual makes during a typical day were made with maximum vigilance and thoroughness, the individual would be unable to function effectively.

64 See Noel Capon \& Roger Davis, Basic Cognitive Ability Measures as Predictors of Consumer Information Processing Strategies, 11 J. CONSUMER RES. 551, 552 (1984).

65 See supra note 62.

66 See supra notes 25-30. 
exerts little cognitive effort while making the source-identification judgment, the individual is more likely to experience source confusion. ${ }^{67}$

This analysis can be employed to refine the terminology employed in the case law. "Sophistication" and "consumer care" are used almost interchangeably by the courts ${ }^{68}$ but the terms are not precisely synonymous. Instead, sophistication is an antecedent of consumer care. Consumers can be said to be "sophisticated" when they have both the motivation and ability to exercise a high degree of consumer care when performing the sourceidentification judgment. Thus a "sophisticated" consumer emerges from the confluence of motivation and ability.

In the sub-sections below, we explain the considerations identified in the consumer behavior literature as relevant to consumer motivation and ability to process information carefully. For clarity of exposition here, the elements of the model are illustrated in Figure 1 below (with outline headings that correspond to the sub-sections that expand on these elements below).

67 See Howard et al., supra note 60, at 261.

68 See, e.g., Kellogg Co. v. Toucan Golf, Inc., 337 F.3d 616, 623 (6th Cir. 2003) (characterizing this factor as "the probable degree of purchaser care and sophistication"); Bristol-Myers Squibb Co. v. McNeilP.P.C., Inc., 973 F.2d 1033, 1046 (2d Cir. 1992) ( "[T] he more sophisticated and careful the average consumer of a product is, the less likely it is that similarities in trade dress or trade marks will result in confusion concerning the source or sponsorship of the product."). 
Figure 1: A Consumer Psychology Model of Sophistication Where Both Motivation and Ability are Antecedents to the Exercise of a High Degree of Care

\section{Extent of Cognitive Effort Degree of Consumer Care}

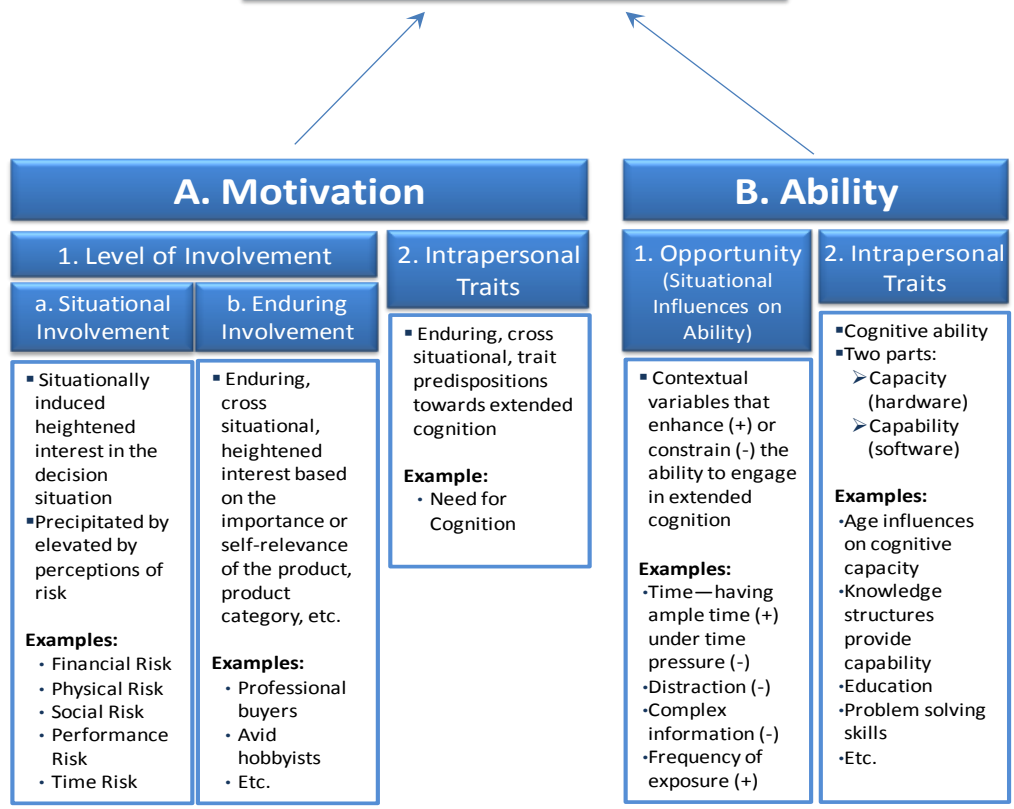

\section{A. Motivation to Exercise Consumer Care}

We first turn our attention to motivation for consumer care. There are both situational and intrapersonal factors that work to increase or decrease consumer motivation to exercise care. One key antecedent of motivation is a consumer's level of involvement with the purchase or consumption situation. Another component of motivation-referred to in the literature as "need for cognition" ${ }^{\circ 9}$-is an enduring, intrapersonal trait that can directly influence a consumer's motivation for care. We first detail the influence a consumer's

69 John T. Cacioppo \& Richard E. Petty, The Need for Cognition, 42 J. PERSONALITY \& Soc. PsyChOL. $116,116(1982)$. 
level of involvement has on motivation and then turn to a careful examination of "need for cognition."

\section{Involvement}

In consumer research, a consumer's level of product involvement is a heavily researched construct directly related to the consumer's motivation to expend cognitive effort. ${ }^{70}$ The perception of personal relevance or salience is the essential characteristic of involvement. ${ }^{71}$ Consumers experience a psychological state of cognitive arousal referred to as high "felt" involvement when they perceive a connection between themselves and the product, the brand, the product category, the consumption activity, or the purchase situation. $^{72}$ Highly involved consumers are highly motivated to exercise consumer care during the source-identification judgment. In contrast, many consumers perceive little connection between themselves and a product, which can be said to constitute a low level of involvement. Routine repurchases and impulse buys for low-cost items are prototypical examples of low-involvement situations. Low levels of felt involvement will not motivate a consumer to exercise consumer care. This does not suggest that consumers with low feltinvolvement will necessarily have low motivation; other factors (as described below) can influence motivation. Thus, what can be said is that that high levels of felt involvement increase motivation and low levels of felt involvement fail to increase motivation. ${ }^{73}$

As developed in the consumer behavior literature, ${ }^{74}$ there are two types of felt involvement: enduring involvement and situational involvement. As described below, the two types of involvement differ in terms of their antecedents and their consequences.

70 For an extensive review, see PIRJO LAAKSONEN, CONSUMER INVOLVEMENT: CONCEPTS AND RESEARCH (1994).

71 Richard L. Celsi \& Jerry C. Olson, The Role of Involvement in Attention and Comprehension Processes, 15 J. CONSUMER Res. 210, 211 (1988).

72 Herbert E. Krugman, The Impact of Television Advertising: Learning Without Involvement, 24 PUB. OPINION Q. 161, 161 (1965). Krugman was the first to research consumer involvement. He showed that consumers were more involved with television advertising when there is a high "number of conscious 'bridging experiences,' connections or personal references per minute that the viewer makes between his own life and the stimulus." Id.

73 Celsi \& Olson, supra note 71, at 212.

74 See Michael J. Houston \& Michael L. Rothschild, Conceptual and Methodological Perspectives on Involvement, in RESEARCHING FronTIERS IN MARKETING: DiAlOGUES AND DiRECTIONS 184, 184 (Subhash C. Jain ed., 1978) (introducing the bifurcated situational/enduring involvement framework). 


\section{a. Enduring Involvement}

A consumer is said to have enduring involvement in a product that she is simply "into"-whether by way of a hobby, an occupation, or some other enduring interest. ${ }^{75}$ Such enduring involvement transcends any one specific encounter with the product (such as the purchase situation) and motivates consumers across multiple product experiences and interactions. To give one example, Harley Davidson customers often have high enduring involvementto the extent that their fixation and interest in the product and brand is based on their trans-situational interest in the product and its associated lifestyle. For such customers, Harley Davidson is a brand closely related to their personal identity and sense of self ${ }^{76}$ and, as such, acts as an intrinsic source of personal relevance $^{77}$ that predisposes them to the experience of felt involvement across time and in varied contexts. ${ }^{78}$ The expected universe of products for which any given consumer has high enduring involvement is relatively small. ${ }^{79}$

\section{b. Situational Involvement and Perceived Risk}

In contrast to enduring involvement, situational involvement is cued by the purchase situation, including those elements of the situation that are directly related to the perceived risk of purchasing and consuming the product. ${ }^{80}$ Ceteris paribus, as a consumer perceives higher levels of risk in a purchase, she experiences higher levels of situational involvement ${ }^{81}$ and is, therefore, motivated to exercise greater consumer care during the source-identification judgment.

75 See Celsi \& Olson, supra note 71, at 212.

76 See John W. Schouten \& James H. McAlexander, Subcultures of Consumption: An Ethnography of the New Bikers, 22 J. CONSUMER RES. 43, 55 (1995).

77 See Celsi \& Olson, supra note 71, at 212.

78 See Robin A. Higie \& Lawrence F. Feick, Enduring Involvement: Conceptual and Measurement Issues, in 16 AdVANCES IN CONSUMER RESEARCH 690, 693 (Thomas K. Srull ed., 1989) (noting that two distinct components of involvement over time are hedonism and self-expression).

79 See LAAKSONEN, supra note 70, at 172.

80 See Peter H. Bloch \& Marsha L. Richins, A Theoretical Model for the Study of Product Importance Perceptions, 47 J. Marketing 69, 70 (1983); see also Utpal M. Dholakia, A Motivational Process Model of Product Involvement and Consumer Risk Perception, 35 EUROPEAN J. MARKETING 1340, 1342 (2001) (showing that the personal salience of a situation is predicted on differing kinds of perceived risk to the consumer in that context).

81 Sharon E. Beatty \& Scott M. Smith, External Search Effort: An Investigation Across Several Product Categories, 14 J. CONSUMER RES. 83, 83-95 (1987); see also Peter H. Bloch et al., Consumer Search: An Extended Framework, 13 J. CONSUMER RES. 119, 120 (1986) (showing that consumers engage in greater and more careful product search when involvement is high). 
An important distinction must be made between perceived risk and objective risk. All that is necessary to bring about situational involvement is for the consumer to perceive risk. ${ }^{82}$ Whether the consumer's risk perceptions are objectively correct is irrelevant. For example, if most consumers perceive little or no physical risk associated with the purchase and use of a new outdoor grill, expert testimony indicating that injuries related to outdoor grills are, in fact, commonplace would be irrelevant to situational involvement. For the same reason, commonly experienced consumer fears lead to perceptions of risk, even if those fears are irrational or objectively unfounded.

Several types of perceived risk have been identified in the literature as impacting situational involvement. ${ }^{83}$ For example, situational involvement increases when consumers perceive a heightened physical risk (i.e., risk of bodily harm) in either the purchase or use of a product or service. ${ }^{84}$ Additionally, perceptions of performance risk increase when there is greater uncertainty about whether a product will perform as expected. ${ }^{85}$ Such perceptions are often related to product quality considerations. When a product is relatively expensive (a perception that depends on the relationship between the price and the customer's available funds), consumers' perceptions of financial risk increase. Thus, consumers buying an automobile typically perceive financial risk because the purchase is a large percentage of their households' disposable income. Time risk reflects the expected duration of the purchase process and the perceived length of ownership. ${ }^{86}$ As the perceptions of the time horizon of ownership expands, so too does the perceived risk associated with the purchase situation. Thus, for most people, buying a durable good, such as a dishwasher, is situationally involving not only because it is relatively expensive, but also because consumers expect to live with the product for several years. Finally, social risk relates to the possible negative reactions of other people if the consumer purchases or consumes the product. ${ }^{87}$ Because a gift-giver is typically trying to please another person, gift-giving inherently carries high social risk. Likewise, if a consumer judges that harm

82 See Vincent-Wayne Mitchell, Consumer Perceived Risk: Conceptualizations \& Models, 33 EUROPEAN J. MARKETING, 163, 163-95 (1995) (discussing the relationship between perceived risk and the level of consumer involvement and trust, as well as the various models used to measure this relationship).

83 See Jacob Jacoby \& Leon Kaplan, The Components of Perceived Risk, in 3 ADVANCES IN CONSUMER RESEARCH, 382, 383 (M. Venkatesan ed., 1972); Ted Roselius, Consumer Rankings of Risk Reduction Methods, 35 J. MARKETING 56, 58 (1971).

84 Jacoby \& Kaplan, supra note 83 , at 383.

85 Id.

86 Roselius, supra note 83 , at 58.

87 Jacoby \& Kaplan, supra note 83 , at 383. 
will come to her social standing if the wrong product is chosen (e.g., if she buys eyeglasses that are long out of style), then social risk is said to be high. In general, when the purchase or consumption of goods or services is interpersonally open to display, perceptions of social risk increase. ${ }^{88}$ A high level of any of these five perceived risks causes consumers to be situationally involved and, therefore, motivated to exercise consumer care while making product judgments. In effect, the consumer carefully deliberates product judgments in the hope that the perceived risks of the buying situation will be mitigated.

\section{Intrapersonal Trait Influences on Motivation}

The consumer psychology literature also suggests that consumers have traits that consistently impact motivation to exert cognitive effort across a variety of situations. For example, some consumers just enjoy thinking more than others. It is part of who they are. Research has identified among such consumers a high "need for cognition." 89 Consumers with a high need for cognition enjoy thinking deeply. They derive "intrinsic enjoyment" from "engaging in effortful information processing." 90 They tend to exert cognitive effort to carefully consider consumer problems (e.g., carefully considering the attributes and benefits of a product before purchasing it). ${ }^{91}$ On the other hand, consumers with a low need for cognition do not enjoy exerting cognitive effort and tend to avoid exerting such effort whenever possible, preferring instead to rely on their intuitions and emotions as their guides. It must be emphasized that need for cognition is a motivational variable, not an ability variable. It is not necessarily the case that consumers in high need for cognition are more intelligent ${ }^{92}$ than their low need for cognition counterparts. ${ }^{93}$ Consumers high

88 See, e.g., Cornelia Pechmann et al., What to Convey in Antismoking Advertisements for Adolescents: The Use of Protective Motivation Theory to Identify Effective Message Themes, 67 J. MARKETING 1, 1-18 (2003) (showing that anti-smoking advertisements showing severe social disapproval of smoking are more effective in curbing underage smoking than those that do not).

89 Cacioppo \& Petty, supra note 69, at 116.

90 John T. Cacioppo et al., Central and Peripheral Routes to Persuasion: An Individual Difference Perspective, 51 J. PERSONALITY \& SOC. PSYCHOL. 1032, 1033 (1986).

91 Curtis P. Haugtvedt et al., Need for Cognition and Advertising: Understanding the Role of Personality Variables in Consumer Behavior, 1 J. CONSUMER PSYCHOL. 239, 247 (1992).

92 Intelligence, as will be discussed in a subsequent section, relates to ability to exert consumer care. See infra text accompanying notes 101-37.

93 See John T. Cacioppo et al., Dispositional Differences in Cognitive Motivation: The Life and Times of Individuals Varying in Need for Cognition, 119 PSYCHOL. BULL. 197, 207 (1996) (noting that correlations between the need for cognition and measures of intellectual ability have proved to be quite low, ranging from -0.03 to 0.32 ). 
in need for cognition do, however, enjoy cognition and thus are relatively more motivated to engage in extended thought.

Relating the need for cognition to the idea of cognitive misers discussed previously,${ }^{94}$ it can be said that individuals who are high in need for cognition are less miserly in their exertion of cognitive effort than individuals who are low in need for cognition. Need for cognition is a stable intrapersonal trait variable that has a reliable influence on a person's motivation to allocate cognitive effort.

Research suggests that as compared to consumers who are low in need for cognition, those who are high in need for cognition engage more thoroughly in information search ${ }^{95}$ regarding potential purchases and respond differently to advertising and other persuasive campaigns. ${ }^{96}$ Consumers high in need for cognition tend to focus on substantive message components in advertisements and ignore extraneous information, such as attractive photographs, humor, and celebrity spokespeople. ${ }^{97}$ Thus, a consumer's need for cognition is an enduring trait predisposition that likely correlates in general terms with Barton Beebe's notion of "search" sophistication. ${ }^{98}$ Consumers high in need for cognition search for information more extensively and process the information they find more carefully. ${ }^{99}$

Need for cognition is of legal relevance because consumers differing in their need for cognition can be expected to have differing product interests. For example, consumers high in need for cognition may gravitate toward products and consumption experiences that provide opportunities for the exertion of cognitive effort, such as chess, strategy games, educational experiences and television shows like Jeopardy. ${ }^{100}$ Because a high need for cognition is likely commonplace among consumers of such products, motivation for care will be relatively higher in markets of such product categories, thus reducing (ceteris paribus) the likelihood of confusion.

\footnotetext{
94 See supra text accompanying note 62.

95 Bas Verplanken et al., Need for Cognition and External Information Search Effort, 26 J. RES. PERSONALITY 128, 129 (1992).

96 John T. Cacioppo et al., Effects of Need for Cognition on Message Evaluation, Recall, and Persuasion, 45 J. Personality \& Soc. Psychol. 805, 809 (1983).

97 See David W. Schumann et al., Predicting the Effectiveness of Different Strategies of Advertising Variation: A Test of the Repetition-Variation Hypotheses, 17 J. CONSUMER RES. 192, 201 (1990).

98 See Beebe, supra note 8, at 2035 (2005).

99 See generally Cacioppo et al., supra note 93.

100 See Wayne D. Hoyer \& Deborah J. Macinnis, Consumer Behavior 381 (4th ed. 2007).
} 


\section{B. Ability to Exercise Consumer Care}

As noted above, high motivation is a necessary but insufficient condition for a consumer to exercise a high degree of care when performing the sourceidentification judgment. The other necessary but insufficient condition is the consumer's ability to exercise consumer care. As with the motivational construct, and as presented in Figure 1, both situational and intrapersonal factors influence a consumer's ability to exercise consumer care and thereby influence the likelihood that an individual consumer will suffer from source confusion. Situational influences on ability are discussed under the rubric of "opportunity," whereas intrapersonal trait influences on ability are denominated "capacity" and "capability."

Ability is generally defined in the consumer behavior literature as the extent to which the consumer has available the cognitive resources requisite to exercise consumer care during information processing and decision making. ${ }^{101}$ To claim that the consumer's ability is high is to assert that when making the source-identification judgment, the consumer is capable of gathering whatever information is desired, capable of comprehending and considering the information, and capable of exerting the cognitive effort necessary to systematically and thoroughly make the source-identification judgment. If the consumer's ability is low, she will be inhibited in her ability to exercise consumer care while making the source-identification judgment. ${ }^{102}$

\section{Situational Influences on Ability: Opportunity}

Situational factors that constrain the ability of consumers to engage in extended cognition, and thus exercise consumer care, include distracting environments, limited information, limited opportunities for comparison, incomprehensible information, and restrictions on time. ${ }^{103}$ Concomitantly, multiple exposures to relevant information across decision experiences can enhance consumers' opportunities to exercise consumer care while making the source-identification judgment. ${ }^{104}$

101 See, e.g., Deborah J. Maclnnis \& Bernard J. Jaworski, Information Processing from Advertisements: Toward an Integrative Framework, 53 J. MARKETING 1, 6-7 (1989).

102 Id. at 7.

103 Id.

104 Id. 


\section{a. Distracting Environments}

Distraction is any aspect of the purchase environment that diverts cognitive resources and attention away from pertinent information. ${ }^{105}$ Background music can act as a distraction that inhibits opportunity to engage in extended thought. ${ }^{106}$ For example, as a consumer at a bar attempts to choose from a long list of lagers, she may be distracted by the bar's loud music. Similarly, loud noise and physical discomfort, such as illness, misbehaving children, and scents in the air, ${ }^{107}$ can all act as distractions in a purchasing environment. Also, aggressive salespeople often distract consumers from the opportunity for thought afforded by a self-paced information search and deliberation by interrupting with questions and conversation. ${ }^{108}$ The result of such distractions is that consumers have less opportunity to exercise consumer care during the source-identification judgment, thereby increasing the likelihood of source confusion. ${ }^{109}$

\section{b. Limited Information}

Purchase environments may also limit the opportunity of consumers to gather information that would be relevant to the source-identification judgment, thereby reducing the opportunity to effectively perform the judgment. ${ }^{110}$ For example, when making in-home purchases (e.g., as with e-commerce), buyers cannot physically inspect the item before purchase. Similarly, some types of retail display cases inhibit physical inspection. ${ }^{11}$ Physical inspection is the primary way of obtaining information for products

105 Scott B. Mackenzie, The Role of Attention in Mediating the Effect of Advertising on Attribute Importance, 13 J. CONSUMER RES. 174, 178-79 (1986).

106 See Deborah J. MacInnis \& C. Whan Park, The Differential Role of Characteristics of Music on Highand Low-Involvement Consumers' Processing of Ads, 18 J. CONSUMER RES. 161, 163 (1991) (examining a music's fit and ties to past emotion-laden experiences on low- and high-involvement consumers' ad processing).

107 Paula Fitzgerald Bone \& Pam Scholder Ellen, Scents in the Marketplace: Explaining a Fraction of Olfaction, 75 J. RETAILING 243, 251-52 (1999).

108 See Gloria Penn Thomas, The Influence of Processing Conversational Information on Inference, Argument Elaboration, and Memory, 19 J. CONSUMER RES. 83, 83-92 (1992); see also Stephen B. Castleberry \& C. David Shepherd, Effective Interpersonal Listening and Personal Selling, 13 J. Personal SELling \& SAles Mgmt. 35, 36 (1993) (describing effective salespeople as those who exhibit good listening skills, including an avoidance of interrupting customers).

109 See MacInnis \& Jaworski, supra note 101, at 7.

110 See id.

111 Joann Peck \& Terry L. Childers, To Have and to Hold: The Influence of Haptic Information on Product Judgments, 67 J MARKETING 35, 36 (2003). 
that vary in terms of material properties, such as texture and weight. ${ }^{112}$ For example, the scent of perfume and the weight balance of running shoes are physical attributes best evaluated by the consumer's physical examination of the product. Such physical information may strongly indicate source identity, so preventing the gathering of such information can inhibit consumers from effectively making the source-identification judgment.

\section{c. Limited Opportunity to Compare Information}

Consumers may also be inhibited in their opportunity to compare information about the junior and senior trademarks. Limited retail distribution makes such inhibition commonplace. ${ }^{113}$ If a retailer offers for sale items bearing both the junior and senior trademark, shoppers will have ample opportunity to compare the items "side by side," while making a sourceidentification judgment. If, however, the retailer offers for sale only the junior trademark, shoppers are inhibited in their opportunity to compare the junior and senior trademarks, thus reducing shoppers' opportunity to exercise care when making the source-identification judgment. For example, if a consumer shops at a retailer that offers for sale Converz shoes, but not Converse shoes, the consumer will be less able to compare information about the junior and the senior trademarks and will, therefore, be less able to exert consumer care (as compared to a consumer shopping at a retailer that sells both Converz and Converse shoes).

\section{d. Incomprehensible Information}

Even if product information is readily available, consumers will be inhibited in their opportunity to process the information if it is presented in a way that is difficult to comprehend. ${ }^{114}$ For example, even if the product labeling on the junior trademark explicitly describes differences between it and

112 See Joann Peck \& Jennifer Wiggins, It Just Feels Good: Customers' Affective Response to Touch and Its Influence on Persuasion, 70 J. MARKETING 56, 56-57 (2006) (describing the important role physical characteristics of the product play in communicating salient information about the product such as the gel finger-grip on the Paper Mate Dynagrip pen).

113 See MacInnis \& Jaworski, supra note 101, at 3, 7 (describing the essential role of opportunity in product evaluation); see also Beatty \& Smith, supra note 81 , at 84 (showing that greater retail distribution enhances opportunity information search and comparative evaluation while limited retail distribution impedes opportunity); Guliz Ger, Richard Belk \& Dana-Nicoleta Lascu, The Development of Consumer Desire in Marketing and Developing Economies, 20 ADVANCES IN CONSUMER RES. 102, 107 (1993) (describing that when products and brands are scarcely distributed, information is limited and opportunity for processing is inhibited).

114 MacInnis \& Jaworski, supra note 101, at 7. 
the senior trademark, if the label contains obscure technical jargon (common with products such as home theater equipment), numeric data (common with products such as dietary supplements), ${ }^{115}$ or a foreign language (common with products such as French perfumes), the consumer will have reduced opportunity to perform the source-identification judgment.

\section{e. Restrictions on Time}

Harried consumers under time pressure will have limited opportunity to carefully consider product information. ${ }^{116}$ Consumer research has shown that time-pressured consumers use shallow, heuristic processing and consider a more limited array of product information. ${ }^{117}$ Opportunity is also limited by time when information is presented in short bursts and limited-duration windows, ${ }^{118}$ and when consumers cannot control their own rate of exposure to information (as with ads playing on radio and television). ${ }^{119}$

\section{f. Frequency of Exposure}

In contrast to the many situational factors that can act to inhibit opportunity, ${ }^{120}$ one situational factor acts to increase opportunity: multiple exposures to relevant information. ${ }^{121}$ For example, seeing an advertisement or a retail display multiple times increases the opportunity for the information to be considered while the consumer performs the source-identification judgment. Also, if there are many overt steps required to enact a purchase, the opportunity for exposure to relevant information is increased. For example, if a consumer desires to purchase a prescription drug after viewing a direct-toconsumer advertisement sponsored by a pharmaceutical company, the

\footnotetext{
115 Richard F. Yalch \& Rebecca Elmore-Yalch, supra note 56, at 522-27.

116 See Peter Wright, The Harassed Decision Maker: Time Pressures, Distractions, and the Use of Evidence, 59 J. APPLIED PSYCHOL. 555, 555 (1974).

117 Bas Verplanken et al., Need for Cognition and External Information Search: Responses to Time Pressure During Decision-Making, 27 J. Res. Personality 238, 241 (1993); see Rajneesh Suri \& Kent B. Monroe, The Effects of Time Constraints on Consumers' Judgments of Prices and Products, 30 J. CONSUMER RES. 92, 93-94 (2003) (reviewing the literature that suggests that time pressure reduces the ability of a consumer to process information).

118 Danny L. Moore et al., Time Compression, Response Opportunity, and Persuasion, 13 J. CONSUMER RES. 85, 87 (1986).

119 Shelly Chaiken \& Alice H. Eagly, Communication Modality as a Determinant of Message Persuasiveness and Message Comprehensibility, 34 J. Personality \& Soc. Psychol. 605, 605 (1976); see Moore et al., supra note 118, at 85-99.

120 See supra text accompanying notes 105-19.

121 MacInnis \& Jaworski, supra note 101, at 7.
} 
consumer must consult a physician and then visit a pharmacist to have the prescription filled. Each step in the purchase process gives the consumer more opportunity to make (and refine) a source-identification judgment.

\section{Intrapersonal Influences on Ability: Capacity and Capability}

Beyond situational influences on consumers' ability to exercise consumer care, a customer comes to a purchase situation with traits that can either enable or inhibit her ability. This intrapersonal, enduring cognitive ability can be bifurcated in an important way: capacity and capability to exercise consumer care. To understand these distinctions more clearly, it is useful to think of capacity as a "hardware" aspect of cognition and capability as "software." 122 The "hardware" aspect, like a computer, refers to the state or capacity "of the machine"-how much processing power or ability does the consumer bring to a purchase situation? ${ }^{123}$ Some computers simply have faster hardware than others. The "software" aspect, as the metaphor suggests, refers to the existence of past experience, knowledge structures, memories, and expertise available to the consumer when exerting cognitive effort as part of mental processes. ${ }^{124}$ In this sense, capability as "software" refers to the memory structures the mind can use to compare, contrast, counter argue, confirm, integrate, and, in other ways, elaborate upon during the consumer decisionmaking process. ${ }^{125}$

\section{a. Capacity for Exercising Consumer Care: "Hardware"}

Consumer behavior studies suggest that intelligence, education, and age are all directly related to a person's capacity to exercise consumer care. Higher levels of intelligence endow the consumer with greater processing capacity. ${ }^{126}$ Further, much like an upgrade in hardware processing power, greater educational attainment is shown to advance intelligence by improving processing strategies, problem-solving skills, and the ability to parse and apprehend complex information. ${ }^{127}$

122 Arie W. Kruglanski et al., Separate or Equal?: Bimodal Notions of Persuasion and a Single Process “Unimodel," in DuAl-Process Theories in Social Psychology 293, 298-99 (Shelly Chaiken \& Yaacov Trope eds., 1999).

123 Id. at 299.

$124 I d$. at 298.

$125 \mathrm{Id}$.

126 See Rolph E. Anderson \& Marvin A. Jolson, Technical Wording in Advertising: Implications for Market Segmentation, 44 J. MARKETING 57, 63-64 (1980).

127 See Nancy Lampert, Critical Thinking Dispositions as an Outcome of Undergraduate Education, $56 \mathrm{~J}$. GEN. EDUC., 17, 17-18 (2007). 
Age has also been correlated with cognitive capacity, but in a nonmonotonic way. The consumer behavior literature suggests that cognitive capacity increases from childhood to adulthood, but eventually declines due to the effects of aging. ${ }^{128}$ Graphically, the relationship can be expressed in an "inverted U-curve" as cognitive capacity for elaborative processing is plotted against cognitive development. The cognitive abilities of young children are still developing, giving them reduced capacity to apprehend and consider market information. ${ }^{129}$ Furthermore, elderly consumers have been shown to commonly experience diminished cognitive skills and thus a reduced capacity to process market information. ${ }^{130}$

\section{b. Capability for Exercising Consumer Care: "Software"}

Continuing the metaphor introduced earlier, the "software" aspects of innate cognitive skill relate to a consumer's capability to exercise consumer care. "Capability refers to the knower's possession of active cognitive structures (i.e., knowledge structures available in memory) wherein the reasoning process from evidence to conclusion may be carried out."131 Thus, having relatively more extensive knowledge of a particular product or product category (i.e., greater consumer expertise ${ }^{132}$ ) provides an individual's processing-ability "hardware" something to relate to the information in the environment. ${ }^{133}$ In fact, having previous experience with and knowledge of a product and its product category facilitates the acquisition of new information regarding that product and category, while also increasing the efficiency ${ }^{134}$ and accuracy ${ }^{135}$ of the information search.

128 See, e.g., Yany Gregoire, The Impact of Aging on Consumer Responses: What Do We Know?, 30 ADVANCES IN CONSUMER RES. 19, 22 (2003).

$129 I d$. at 19.

130 Catherine A. Cole \& Gary J. Gaeth, Cognitive and Age-Related Differences in the Ability to Use Nutritional Information in a Complex Environment, 27 J. MARKETING RES. 175, 175-84 (1990).

131 Kruglanski et al., supra note 122, at 298.

132 Joseph W. Alba \& J. Wesley Hutchinson, Dimensions of Consumer Expertise, 13 J. CONSUMER RES. 411, 411 (1987).

133 Durairaj Maheswaran \& Brian Sternthal, The Effects of Knowledge, Motivation, and Type of Message on Ad Processing and Product Judgments, 17 J. CONSUMER RES. 66, 66 (1990).

134 See Merrie Brucks, The Effects of Product Class Knowledge on Information Search Behavior, $12 \mathrm{~J}$. CONSUMER RES. 1, 1-16 (1985); Jacoby, supra note 14, at 1023-28.

135 See Cynthia Huffman \& Michael J. Houston, Goal-Oriented Experiences and the Development of Knowledge, 20 J. CONSUMER RES. 190, 190-207 (1993). 
Individuals develop more elaborate knowledge structures around what they experience more frequently. ${ }^{136}$ On this point, the situational influence of repeated encounters with relevant market information (e.g., during consumer decisions that require multiple steps to complete) interacts with the development of knowledge structures to facilitate the performance of the source-identification judgment. Thus, consumers who purchase the same product frequently have greater knowledge in that category, which amounts to an increase in capability. Similarly, consumers exposed to repeated advertising are more likely to develop richer product knowledge structures that are facilitative of consumer care. ${ }^{137}$

In sum, the consumer behavior literature suggests that if an individual lacks either motivation or ability to expend cognitive effort while making the sourceidentification judgment, she will perform the judgment in a haphazard and offhand manner, resulting in an increased likelihood of confusion. A consumer may be motivated to exercise a high degree of care by any one of a number of factors: enduring involvement, situational involvement (precipitated by risk perceptions), or need for cognition. A consumer's ability to exercise a high degree of care may be inhibited by distractions in the shopping environment, limited availability of information, limited opportunity to compare the junior and senior trademarks, incomprehensible information, and restrictions on time. Conversely, a consumer's ability can be increased through multiple exposures to product information and a multiple-step purchase process. As described in the next Part, these principles allow detailed predictions regarding the circumstances in which consumers can be expected to experience source confusion.

\section{The CONSUMER BeHAVIOR MOdel AS A CONSTRUCt For Evaluating JUDICIAL CONCEPTIONS OF CONSUMER SOPHISTICATION AND CARE}

The judicial evaluation of consumer "care" and "sophistication" has not, as yet, tapped into the insights of the consumer behavior literature. Instead, the case law in this field has unfolded in an unsystematic, ad hoc manner, with the courts being guided by intuition and (eventually) precedent, and not by any comprehensive theoretical principles. Thus, there is a fundamental disconnect between a field of law that is premised on assumptions about consumer behavior and a well-developed body of literature studying those very

\footnotetext{
136 C. Whan Park et al., Consumer Knowledge Assessment, 21 J. CONSUMER Res. 71, 71 (1994).

137 See Alba \& Hutchinson, supra note 132, at 415-17.
} 
assumptions. This is unfortunate, as the consumer behavior model provides powerful theoretical tools for understanding and analyzing judicial intimations about consumer sophistication.

We seek to remedy this disconnect here. In the sections below, we evaluate some of the principal strands of the consumer sophistication case law through the lens of the consumer behavior model. The discussion proceeds on two levels. On some points, we offer a "positive" analysis of the case law, which, though built on intuition and without any comprehensive theoretical foundation, turns out in many respects to find support in the consumer behavior model. To this extent, the contribution of our model is to provide a sound framework for understanding the existing case law and thus to facilitate its evolution and development over time. Second, in other instances, we find the case law's intuitive assessments to be faulty, or at least shortsighted, and to this extent we offer a "normative" analysis. On these issues, we propose a change in the direction of the current case law - a change that is necessary where sound theoretical principles contradict ad hoc judicial intuition.

The sections below address several lines of cases in which the courts have evaluated the degree of consumer care or sophistication. Specifically, we consider cases in which the courts have identified price, length and complexity of the purchase transaction, frequency of purchase, education, age, and income as factors relevant to the expected degree of consumer care, as well as cases in which the target market consists of professional buyers or avid hobbyists. Our analysis of these cases demonstrates that the consumer is neither the "fool," as the apologist commentator would have it, nor the informed "sovereign," as the restrictionists posit. Instead, the consumer exhibits characteristics of both, depending on the circumstances. She devotes extensive cognitive energy to the source-identification judgment only where she is motivated and able to do so; where either or both of these preconditions are absent, her involvement in source-identification will be limited-not because she is a "fool" or a "presumptive idiot," but because she is following the same human tendencies that we all possess. ${ }^{138}$

138 See generally, Adam Benforado \& Jon Hanson, The Great Attributional Divide: How Divergent Views of Human Behavior Are Shaping Legal Policy, 57 EMORY L.J. 311 (2008) (Discussing the causes and effects of these tendencies). 


\section{A. Price}

The courts have long embraced the notion that consumer care is affected by price. Where "goods or services are relatively expensive," the courts anticipate that "more care is taken" at the point of purchase and that "buyers are less likely to be confused as to source or affiliation." "139 As one court put it, "the average purchaser of an automobile will no doubt devote more attention to examining different products and determining the manufacturer or source than will the average purchaser of a ball of twine." ${ }^{140}$ Examples of expensive items thought to indicate high consumer involvement include boats, ${ }^{141}$ cameras, ${ }^{142}$ high-end home exercise equipment, ${ }^{143}$ guitars, ${ }^{144}$ sound design services, ${ }^{145}$ trade association memberships, ${ }^{146}$ cruise ship tickets, ${ }^{147}$ waste-water treatment devices, ${ }^{148}$ mortgages, ${ }^{149}$ golf club memberships, ${ }^{150}$ and real estate. ${ }^{151}$

Conversely, where the "products are relatively low-priced and subject to impulse buying, the risk of likelihood of confusion is increased." 152 For example, "inexpensive snack foods" are expected to be "purchased with little care" under circumstances where consumer confusion is likely. ${ }^{153}$ By the same token, "[t]he ordinary purchaser of bread and margarine is a casual buyer,"

139 Checkpoint Sys., Inc. v. Check Point Software Techs., Inc., 269 F.3d 270, 284 (3d Cir. 2001) (citing MCCARTHY, supra note 2, § 23:95).

140 McGregor-Doniger Inc. v. Drizzle Inc., 599 F.2d 1126, 1137 (2d Cir. 1979).

141 See AMF Inc. v. Sleekcraft Boats, 599 F.2d 341, 354 (9th Cir. 1979); HBP, Inc. v. Am. Marine Holdings, Inc., 290 F. Supp. 2d 1320, 1335-36 (M.D. Fla. 2003).

142 See Omega Importing Corp. v. Petri-Kine Camera Co., 451 F.2d 1190, 1195 (2d Cir. 1971).

143 See Nautilus Group, Inc. v. Savvier, Inc., 427 F. Supp. 2d 990, 998-99 (W.D. Wash. 2006); Nautilus Group, Inc. v. Icon Health \& Fitness, Inc., 308 F. Supp. 2d 1208, 1212 (W.D. Wash. 2003).

144 See Switchmusic.com, Inc. v. U.S. Music Corp., 416 F. Supp. 2d 812, 824-25 (C.D. Cal. 2006).

145 See Mach. Head v. Dewey Global Holdings, Inc., 61 U.S.P.Q.2d 1313, 1320-21 (N.D. Cal. 2001).

146 See Self-Ins. Inst. of Am., Inc. v. Software \& Info. Indus. Ass'n, 208 F. Supp. 2d 1058, 1073 (C.D. Cal. 2000).

147 See Carnival Corp. v. SeaEscape Casino Cruises, Inc., 74 F. Supp. 2d 1261, 1267 (S.D. Fla. 1999).

148 See Jet, Inc. v. Sewage Aeration Sys., 165 F.3d 419, 422-23 (6th Cir. 1999).

149 See First Franklin Fin. Corp. v. Franklin First Fin., Ltd., 356 F. Supp. 2d 1048, 1052 (N.D. Cal. 2005).

150 See Champions Golf Club, Inc. v. The Champions Golf Club, Ltd. 78 F.3d 1111, 1120-21 (6th Cir. 1996).

151 See Homeowners Group, Inc. v. Home Mktg. Specialists, Inc., 931 F.2d 1100, 1111 (6th Cir. 1991) (finding that 'in this case it appears that the buyers of both Homeowners' and Specialists' [two real-estate brokers] services are likely to exercise a high degree of care").

152 Recot, Inc. v. M.C. Becton, 214 F.3d 1322, 1329 (Fed. Cir. 2000); see also Patsy’s Brand, Inc. v. I.O.B. Realty, Inc., 317 F.3d 209, 219 (2d Cir. 2003) (finding that consumer sophistication and degree of care exercised is low when purchasing cheaper products sold in grocery stores).

153 Beer Nuts, Inc., v. Clover Club Foods Co., 805 F.2d 920, 926-27 (10th Cir. 1986); see also id. at 926 ("[A] secondary trademark on a small, inexpensive item such as a package of nuts does not eliminate the possibility of confusion because consumers exercise little care in purchasing these products.”). 
particularly in "the bustling, self-service atmosphere of a typical supermarket." 154 Other examples of inexpensive purchases that correlate with lower consumer care include sporting goods, ${ }^{155}$ over-the-counter sleep medicine, ${ }^{156}$ business training programs,${ }^{157}$ some kinds of wine,${ }^{158}$ kitchen accessories, ${ }^{159}$ air fresheners, ${ }^{160}$ t-shirts, ${ }^{161}$ and magazines. ${ }^{162}$

The basic relationship between price and consumer care finds theoretical support in the motivation element of the consumer behavior model. According to this model, price is correlated positively with perceived financial risk. Thus, holding all other factors constant, as price increases so does situational involvement - an antecedent of the consumer's motivation to exert consumer care while making the source-identification judgment. To this extent, the courts' intuitive assessment of the relevance of price rests on sound theoretical footing.

That is not to say that the consumer behavior model supports the notion of designating price as a dispositive factor. While higher prices generally are thought to heighten perceptions of financial risk for most consumers, consumer behavior theory reveals that the level of involvement is not intrinsic to the product, but is relative to the consumer as the perceiver. In other words, involvement is in the eye of the consumer and not intrinsic to product or service per se. It is a bit of a misnomer to call an expensive good a "highinvolvement product."

Thus, the consumer behavior model suggests an important adjustment to the courts' treatment of price as a proxy for consumer sophistication. Under our model, price may correlate with the level of care exercised by the consumer, but only to the extent that the financial risk-factor identified in the involvement construct outweighs any other relevant involvement factors that may point in the other direction. In some cases, certain factors other than price

\footnotetext{
154 Lever Bros. Co. v. Am. Bakeries Co., 693 F.2d 251, 259 (2d Cir. 1982) (implying that self-service markets' low prices and bustling atmosphere leave room for high likelihood of confusion).

155 See Sports Auth., Inc. v. Prime Hospitality Corp., 89 F.3d 955, 965 (2d Cir. 1996).

156 See Bristol-Myers Squibb Co. v. McNeil-P.P.C., Inc., 973 F.2d 1033, 1046-47 (2d Cir. 1992).

157 See Forum Corp. of N. Am. v. Forum, Ltd., 903 F.2d 434, 442 (7th Cir. 1990).

158 See Vigneron Partners, LLC v. Woop Woop Wines Pty Ltd., 2006 WL 1214859, at *7-8 (N.D. Cal. May 5, 2006).

159 See Keystone Mfg. Co., Inc. v. Jaccard Corp., 394 F. Supp. 2d 543, 559 (W.D.N.Y. 2005).

160 See Car-Freshner Corp. v. Big Lots Stores, Inc., 314 F. Supp. 2d 145, 152 (N.D.N.Y. 2004).

161 See World Wrestling Fed'n Entm't Inc. v. Big Dog Holdings, Inc., 280 F. Supp. 2d 413, 436 (W.D. Pa. 2003).

162 See Brockmeyer v. Hearst Corp., 248 F. Supp. 2d 281, 299 (S.D.N.Y. 2003).
} 
would reinforce the usual correlation between price and consumer care. For certain products like apparel and jewelry, for example, high involvement may be cued not only because of the financial risks associated with high price, but also in light of the potential social risks presented. ${ }^{163}$ For other products, like high-end climbing equipment, the involvement motivation flowing from the financial risks associated with a hefty price tag would be reinforced by physical risks. ${ }^{164}$

In some situations and market segments, however, we might expect an expensive product to be a low-involvement purchase; in other circumstances, we might expect high involvement, even in the purchase of relatively inexpensive items. Even a low-priced item might rate high on the motivation scale, for example, if it presents significant physical risks. In situations where the use of the product or service may involve the potential for tangible harm, consumers generally will be more situationally involved and process relevant information more systematically and carefully. ${ }^{165}$ In the following sections, we identify circumstances in which (1) even high-priced goods cannot be expected to engender sufficient levels of exercised care; and (2) low-priced goods might nonetheless produce incentives for exercised care.

\section{High-Prices, Yet Insufficient Levels of Consumer Care}

Our model provides a framework for identifying circumstances where even high-priced goods may not be expected to produce consumer care that is sufficient to dispel confusion. First, high prices will trigger motivation for care only where they give rise to perceived financial risk. Thus, the significance of

163 See J.R. Wood \& Sons v. Reese Jewelry Corp., 278 F.2d 157, 159 (2d Cir. 1960) (finding sophistication on the part of consumers of wedding and engagement rings); see also E.T.F. Enters., Inc. v. Nina Ricci, S.A.R.L., 523 F. Supp. 1147, 1156 (S.D.N.Y. 1981) (asserting that fashion-conscious customers of clothing, fragrances, and accessories "are not likely to be misled by two marks which share the same surname but have different first names").

164 See S. Indus., Inc. v. Stone Age Equip., Inc., 12 F. Supp. 2d 796, 816 (N.D. Ill. 1998) (noting that "[s]electing a shoe to wear for climbing treacherous peaks . . requires careful examination and inquiry about the sole's gripping characteristics and ability to withstand these extraordinary uses," and concluding that "at $\$ 140$ a pair, customers will not make the purchase lightly”); see also Bioglan Inc. v. Bioglan Labs. Ltd., 44 U.S.P.Q.2d 1662, 1667 (C.D. Cal. 1997) (indicating that purchasers of healthcare-related products are likely to exercise some degree of care); Blansett Pharmacal Co. v. Carmrick Labs. Inc., 25 U.S.P.Q.2d 1473, 1477 (T.T.A.B. 1992) (applying the "doctrine of greater care" in asserting that it is more important to avoid confusion with respect to pharmaceuticals because of the potential for serious medical consequences). But see Eli Lilly \& Co. v. Natural Answers, Inc., 233 F.3d 456, 464 (7th Cir. 2000) (suggesting that "there is just no evidence that consumers as a whole are extraordinarily careful when it comes to dietary supplements").

165 See Celsi, supra note 84, at 1-23 (detailing the extent of involvement exhibited by consumers purchasing and participating in high-physical-risk consumption). 
price in the consumer-care function should be evaluated relative to the income or wealth of the target demographic. If a certain product is targeted at a particularly wealthy clientele, a price tag that might seem high to an average consumer-i.e., one that would generate perceived financial risk-may not have the same effect. ${ }^{166}$

Second, even where a consumer's perception of financial risk is high, the model does not predict a high level of consumer care where there are significant constraints on opportunity for care. After all, motivation is only one factor in the consumer care function; even a motivated consumer will not be careful if her ability to be careful is limited by environmental constraints.

Consider the case of Karen J. Connelly, S.Y.K., LLC v. ValueVision Media, Inc. ${ }^{167}$ where the court assessed the degree of care expected of consumers of jewelry sold through "home shopping" television outlets. ${ }^{168}$ Although the jewelry was "not inexpensive (ranging from a few hundred to thousands of dollars)," the court nonetheless concluded that consumers of such items were not sophisticated. ${ }^{169}$ The court based its conclusion on its understanding of the "nature of home shopping, where consumers do not actually inspect items prior to purchase." 170 This analysis can be translated in terms of our model in opportunity terms. The television home shopping context may be one in which a consumer's motivation for enhanced involvement in a high-priced (and thus high-financial-risk) purchase might be overcome by the consumer's reduced opportunity to gather information by physically inspecting the product prior to purchase, thus reducing their ability to engage in extended cognition. Thus, the home shopping buyer of jewelry may be sufficiently motivated to be careful, but constraints on opportunity may still give reason to rate the level of consumer care as relatively low. ${ }^{171}$

\footnotetext{
166 At least one court has proffered the converse conclusion (albeit without pinpointing the issue as one of “perceived risk”). See Reebok Intern. Ltd. v. K-Mart Corp., 849 F. Supp. 252, 268 (S.D.N.Y. 1994) ("In fact, an argument can be made that shoppers with limited budgets use more care in spending their more limited resources than shoppers at non-discount stores.").

1672004 WL 2569494 (D. Minn. Nov. 9, 2004).

$168 I d$. at $* 1$.

169 Id. at $* 7$.

$170 \mathrm{Id}$.

171 As explained in greater detail infra notes 215-16, there may be reason to be skeptical about the effect of such constraints on opportunity. The very context identified by the court - the home shopping environment in which "consumers do not actually inspect items prior to purchase"-may further enhance a consumer's motivation for extended cognition. Karen J. Connelly, S.Y.K., LLC, 2004 WL 2569494, at *7. Specifically, in the context of a jewelry purchase in a home-shopping environment, the consumer has limited information about the product that she purchases, little confidence in or experience with the product, and an expectation of
} 
Even where financial risk is not outweighed by other elements, the model identifies additional grounds for rejecting the usual presumption that high price will engender care sufficient to reduce the likelihood of confusion. Under the model, the exercise of consumer care is relevant only to the extent that the exertion of additional cognitive effort can be expected to dispel confusion. If it will not, as in a case involving identical marks in direct competition with each other, even a relatively high degree of consumer care will not be sufficient.

This analysis explains decisions like Omega Importing Corp. v. Petri-Kine Camera Co. ${ }^{172}$ in which the court found a likelihood of confusion arising out of the junior's use of the EXAKTA trademark in direct competition with the senior's use of the identical trademark on high-priced cameras. ${ }^{173}$ Although the court acknowledged that "the cameras here in question are expensive items" with respect to which the "purchaser would be expected to make more than a casual inspection of the product before buying," "purchaser inspection would be of doubtful value." consistent with our model. If even relatively high levels of cognition cannot dispel confusion between facially identical trademarks, then high price is simply beside the point.

\section{Low-Prices, but High Levels of Consumer Care}

Sometimes, even low-priced goods can rate high on the involvement scale, such as in cases where alternative considerations introduce "perceived risk" beyond that associated with high price. Worthington Foods v. Kellogg Co. ${ }^{176}$ arguably presents one example. In that case, the court concluded that "heightened awareness of health and healthy foods raises the standard of care which the reasonable purchaser of [healthy foods] would exercise." ${ }^{\text {177 }}$ Thus, although HEARTWISE brand breakfast foods are a low-priced product, they need not reflexively be dumped in the "low consumer-sophistication" basket,

\footnotetext{
an extended experience with a purchase that may involve strong self-presentation aspects. All of these factors will tend to heighten the perceived risks of the purchase (adding performance and social risks to the financial risk already perceived), such that the consumer may be sufficiently motivated to find creative ways to overcome the time limitations of the home shopping environment-such as by waiting until the product is offered a second time or pursuing alternative channels, such as an internet website or toll-free number.

172451 F.2d 1190 (2d Cir. 1971).

173 Id. at 1195.

174 Id.

175 Id.

176732 F. Supp. 1417 (S.D. Ohio 1990).

177 Id. at 1448.
} 
since the physical risk associated with buying purportedly health-conscious foods may enhance the motivation for the exercise of consumer care, even if price alone does not increase consumer perceptions of financial risk. ${ }^{178}$

There may also be circumstances where the financial risk persists even where the price of the product in question is low. Consider the case of ReedUnion Corp. v. Turtle Wax, Inc. ${ }^{179}$ in which the court found that a purchase of inexpensive car polish was nevertheless likely to involve relatively high levels of sophistication. ${ }^{180}$ The court's explanation - that this inexpensive product was to be used on an expensive possession (a car) ${ }^{181}$ — can easily be restated in terms of the motivation factor: Price is only part of the perceived financial risk associated with some purchases, and where use of the product could have a substantial impact on the value of another product, even low-priced purchases may present significant financial risk and thus a high level of situational involvement.

Finally, there may be other low-priced products that would be naturally dominated by high "need for cognition" consumers who would be intrinsically attracted to a product that gives them a chance to exert cognitive effort. Sudoku and other "brain teaser" puzzle books, for example, present low financial risk, but the typical consumer of such products would likely possess a high need for cognition that would suggest higher levels of care regardless of low perceptions of financial risk. Thus, our model suggests some reason to doubt the conclusions of some courts that consumers of such products rate low on the consumer care scale. ${ }^{182}$

178 The apparent perception of this sort of risk might be dampened, however, by the proliferation of purportedly healthy products available to consumers. If consumers are bombarded by health claims, they may tend to discount them, and thus not perceive any risk that would enhance their motivation for extended cognition.

179869 F. Supp. 1304 (N.D. Ill. 1994), aff'd, 77 F.3d 909 (7th Cir. 1996); see also Life Indus. Corp. v. Star Brite Distrib., Inc., 31 F.3d 42, 47 (2d Cir. 1994) (pointing to evidence showing that purchasers of inexpensive boat caulking are sophisticated because "they usually are owners of large, expensive boats with wood decks").

180 Reed-Union Corp., 869 F. Supp. at 1310.

181 Id.

182 See, e.g., Herbko Int'l, Inc. v. Kappa Books, Inc., 308 F.3d 1156, 1166 (Fed. Cir. 2002) (finding that the "sophistication of purchasers" mark weighed in favor of a finding of a likelihood of confusion in a suit by publisher of paperback books under CROSSWORD COMPANION mark for cancellation of same mark on handheld device with scrollable rolls of crossword puzzles); Teaching Co. v. Unapix Entm't, Inc., 87 F. Supp. 2d 567, 585 (E.D. Va. 2000) (finding "no evidence that the consumers of [such] products . . . deserve consideration as sophisticated buyers" in a suit by holder of trademarks GREAT MINDS and GREAT MINDS OF THE WESTERN INTELLECTUAL TRADITION, used in connection with sale of video and audio tapes 


\section{B. Length and Complexity of the Purchase Transaction}

A second factor frequently identified in the case law is the length and complexity of the purchase process. The more time the consumer is expected to devote to purchasing a particular product, the more care she is expected to take. There are two distinct strands of cases: (1) those where the courts have attempted to identify products that are by their very nature likely to be the subject of an "impulse" purchase; and (2) those where the courts have examined the complexity of the purchasing process to determine whether a consumer is likely to engage in high levels of consumer care.

Examples of products deemed inherently "impulsive" include magazines (because consumers are thought to purchase them based on the cover or title), ${ }^{183}$ snack foods (since consumers may purchase them without putting them on their grocery lists) ${ }^{184}$ and fast food (which is purchased when consumers are in a hurry). ${ }^{185}$ With respect to the purchasing process, the courts have sometimes correlated low levels of consumer care with quick or hurried transactions. For example, at least one court has suggested that directorder television advertisements ("infomercials") involve low-care, impulse purchases, since such "advertising is directed toward those persons who tend to buy on impulse when they see a product on television which appeals to them at a reasonable price." 186 Another court offered a similar assessment of the low level of care typically exercised in the "bustling, self-service atmosphere of a typical supermarket." 187

of lectures on great philosophers by leading contemporary scholars, against defendant selling documentary films under the GREAT MINDS mark).

183 See Brockmeyer v. Hearst Corp., 248 F. Supp. 2d 281, 299 (S.D.N.Y. 2003) (generalizing that magazines are impulse purchases); see also Playboy Enter., Inc. v. Chuckleberry Publ'g, Inc., 687 F.2d 563, 570 (2d Cir. 1982) (finding that magazine subtitles contribute greatly to impulse buying).

184 See Gray v. Meijer, Inc., 295 F.3d 641, 649-50 (6th Cir. 2002) (determining that buyers of inexpensive snack foods do not exercise a high degree of care); Beer Nuts, Inc., v. Clover Club Foods Co., 805 F.2d 920, 926-27 (10th Cir. 1986) (finding that there is a high likelihood of confusion in purchasing a snack-nut mix because consumers exercise little care when purchasing competing brands "Beer Nuts" and "Brew Nuts"those items are impulse purchases that are not generally on the consumer's grocery list).

185 See Frisch's Rests. v. Elby's Big Boy, 670 F.2d 642, 648 (6th Cir. 1982) (finding a casual degree of care in "impulse buying" of fast food items); Burger Chef Sys., Inc. v. Burger Man, Inc., 492 F.2d 1398, 1399 (C.C.P.A. 1974) (describing fast-food customers as on the move and in a hurry).

186 Telebrands Corp. v. E. Mishan \& Sons, 46 U.S.P.Q.2d 1493, 1508 (S.D.N.Y. 1997).

187 Lever Bros. v. Am. Bakeries Co., Inc., 537 F. Supp. 248, 255 (E.D.N.Y. 1982) (concluding that "the ordinary purchaser of AUTUMN margarine and AUTUMN GRAIN bread is a casual, unsophisticated buyer," and an atmosphere "in which over 5,000 trademarked items are presented" is unlikely to be conducive to a high level of consumer care). 
Conversely, the courts have also identified circumstances where the purchasing environment is conducive to (or even requires) the exercise of high levels of consumer care. In Star Industries v. Bacardi \& Co., ${ }^{188}$ for example, the court concluded that liquor store purchases are not likely to constrain levels of consumer care - in light of the store's generally relaxed environment as compared to a supermarket. ${ }^{189}$ Alternatively, the courts have found sophistication in circumstances involving extended negotiation and interaction with sales personnel. Examples of purchases deemed to involve this sort of sophistication run the gamut from lawn and garden equipment to perfume. ${ }^{190}$ The assumption is that trained personnel can be expected to "help[] inform customers of the differences in the products." $" 191$

Elsewhere, the courts have concluded that inherently complex transactions can be expected to involve high levels of care. Under this analysis, the courts have held that consumers of certain financial instruments are "sophisticated" because of the steps required to complete a transaction through a financial institution. $^{192}$ On similar analysis, the courts have anticipated high levels of care in the purchase of a health care plan. ${ }^{193}$

188412 F.3d 373 (2d Cir. 2005).

189 Id. at 390 (differentiating the "rough and tumble" atmosphere at grocery stores from the "relaxed environment of the liquor store," where unhurried customers will "exhibit sufficient sophistication" to distinguish between different stylized scripts on the competing brands' labels, thus decreasing likelihood of confusion). Alcoholic beverages are one product category where the courts have sent conflicting signals as to the expected level of consumer care. The conflict in the case law is discussed in some detail infra notes 25257.

190 See, e.g., Deere \& Co. v. MTD Holdings, Inc., 70 U.S.P.Q.2d 1009, 1023 (S.D.N.Y. 2004) (finding that consumer interaction with sales personnel when purchasing expensive lawn and garden maintenance equipment would help to dispel confusion, such that purchasers of such equipment are deemed to exercise a higher degree of care); Conopco, Inc. v. Cosmair, Inc., 49 F. Supp. 2d 242, 257 (S.D.N.Y. 1999) ("There is ample evidence in the record that the purchasers of expensive perfumes from high-end department and specialty stores, who are often assisted by retail selling specialists and beauty advisors, . . . are sophisticated and discriminating consumers.").

191 Frances Rothschild, Inc. v. U.S. Cosmetic Fragrance Mktg. Corp., 223 U.S.P.Q. 817, 818 (N.D. Tex. 1983 ) (indicating that "retailers' utilization of 'demonstrators' (trained sales persons) in the sale of men's fragrance products" informs customers of the differences in the products).

192 Beneficial Corp. v. Beneficial Capital Corp., 529 F. Supp. 445, 450 (S.D.N.Y. 1982) (finding increased sophistication because of complexity of purchasing financial instruments); see also Metlife, Inc. v. Metro. Nat'1 Bank, 388 F. Supp. 2d 223, 235 (S.D.N.Y. 2005) (stating that the key determination is the number of steps required, as well as the value of the financial instruments involved and noting that where consumers merely open a bank account or purchase certificates of deposit, the sophistication level does not necessarily increase).

193 Am. Rep. Ins. Co. v. N. Am. Health Plans, Inc., 1996 U.S. Dist. LEXIS 7568, at *25-26 (W.D.N.Y. May 21, 1996) (stating that because of the time and effort consumers spend evaluating different health care plans, consumer naivety as to the different plans available decreases, so consumers are deemed more sophisticated). 
The consumer behavior model provides a useful framework for evaluating these cases. The impulse-product cases are most naturally evaluated under the motivation construct, which suggests that "impulse" purchases will be those that present little perceived risk. The purchase-process cases implicate the ability construct and the question of whether and to what extent the purchasing environment requires, permits, or limits opportunities for the exercise of care during the source-identification judgment.

As a general matter, we find that judicial intuitions in these cases find support in the theoretical foundations of the model. We also conclude, however, that the model provides a basis for questioning the results in some of the cases and - more broadly - some cautionary limits on further development of the jurisprudence. As with price, we find that judicial intuitions with respect to the time and complexity of the purchase process veer off course where the courts focus myopically on any single factor in the consumer care function. A reliable assessment of the degree of consumer care requires a complete consideration of all of the elements of the consumer behavior model, and the analysis is distorted (as in some of the cases highlighted below) where the courts focus on isolated elements of the model to the exclusion of others.

\section{1. "Impulse Products," Motivation, and Risk}

According to the consumer behavior model, products likely to be purchased on "impulse" are those that present relatively little motivation for the exercise of consumer care. There is some overlap with the price factor discussed above: impulse items will tend to be low in price and thus present little financial risk. But the involvement construct allows us to generalize the "impulse" category beyond price: "impulse" purchases should be defined to encompass products that present minimal motivation for involvement across any of the various risk factors (financial, performance, physical, and social). Thus, under the model, impulse items would encompass lower-cost items that are consumed within a short horizon, that the consumer is relatively familiar with, and for which perceived social and physical risk are relatively low. ${ }^{194}$

Much of the "impulse product" case law finds support in this analysis. Magazines, snack foods, and fast food meet the foregoing criteria; thus, they are likely to present minimal risk (whether financial, performance, physical, or

194 See Richard P. BAgOZZI, PRinCiPLES OF MARKETING MANAGEMENT 61-63 (1986). 
social) and consequently present little motivation for the exercise of consumer care.

The model also provides a limiting principle, however, and thus a basis for confining the "impulse product" categories to their proper bounds. Although impulse products ordinarily implicate a low level of motivation for consumer care, that will not always be so. ${ }^{195}$ Consider health food items. Should such purchases be deemed to involve low levels of consumer care, at least where they may fall under the "snack food" or "fast food" categories? Perhaps not. The question is whether these items present some element of risk as a motivation for the exercise of consumer care-not whether they can fit into some abstract category of "fast food" or "snack food."

At least one court has suggested that consumers may be expected to "purchase "healthy' products quickly, but not impulsively or carelessly." 196 That conclusion is at least arguably consistent with a careful parsing of the involvement construct: such products may not present any significant financial risk or time commitment in the purchase transaction, but they may implicate an element of physical risk that may enhance the motivation for the exercise of consumer care while making the source-identification judgment. ${ }^{197}$ In the health-food niche, consumers may be assumed to be more concerned about physical risk, and thus to expend greater cognitive resources than they would if they were focused only on the (minimal) financial risk associated with a snack food purchase. Thus, the "impulse product" question should be evaluated based on the degree of relative risk factors as motivations for extended involvement, not on blind adherence to precedents identifying broad product categories deemed forever likely to be purchased on impulse.

Some items, such as condoms, would by their nature and use create high involvement and time investment with their purchase because they produce, for

\footnotetext{
195 Recall the Sudoku example above, supra text accompanying note 182, of low-priced products aimed at a customer base that is high in "need for cognition." The point is that perceived financial risk is only one trigger for motivation for consumer care. Where other triggers are present, a product that may ordinarily be thought of as an impulse purchase may nevertheless involve a high degree of consumer care.

196 See Luigino's, Inc. v. Stouffer Corp., 170 F.3d 827, 831 (8th Cir. 1999).

197 See Stouffer Corp. v. Health Valley Natural Foods, Inc., 1 U.S.P.Q.2d 1900, 1902 (T.T.A.B. 1987) ("[D]iet-conscious purchasers of these prepared entrees are a special class of purchasers who may be expected, at least, to examine the front of the packages in order to determine what kind of entree is contained therein and its caloric content."), aff'd, 831 F.2d 306 (Fed. Cir. 1987). Alternatively, with respect to some "niche" or specialty foods, consumers may exhibit a sort of avocational devotion or "enduring involvement" in the product category at issue. The enduring involvement concept is discussed in greater detail infra notes 198207.
} 
many consumers, heightened perceptions of risk (physical, social, etc.) leading to the exercise of high levels of consumer care. A similar example identified in the case law is shoes. At least one court has suggested that even though shoes may be relatively low-priced, they may not properly be classifiable as an impulse item. ${ }^{198}$ The court's conclusions can be understood in terms of the motivation construct: shoes may present physical and social risk as motivations for involvement even if they do not entail any significant financial risk. ${ }^{199}$

\section{Purchase Processes and Effects on Opportunity for the Exertion of Consumer Care}

In the purchase-process cases, the courts have identified purchasing environments that facilitate, foreclose, or even require opportunities for the exercise of consumer care. These cases implicate the ability element of the consumer behavior model, which explains that consumer care may be affected not only by motivation, but also by the degree of opportunity to engage in extended cognition. This construct provides an analytical foundation for understanding these cases. But it also provides a limiting principle to guide the development of the case law and for questioning some of the outcomes in the cases.

\section{a. Unconstrained Opportunity}

In Star Industries, Inc. v. Bacardi \& Co., ${ }^{200}$ the court concluded that the relaxed atmosphere of a liquor store would facilitate consumer care and that consumers in that environment would not likely be confused by defendant Bacardi's use of an elliptical, stylized "O" trademark on its orange-flavored rum - a mark that purportedly was confusingly similar to plaintiff Star Industries' elliptical, stylized "O" mark on its orange-flavored vodka. ${ }^{201}$ This analysis finds an initial foothold in the opportunity element of the ability construct: Consumers who feel at ease in a purchasing environment will not have any limitations placed on their ability to exercise a high degree of

198 See Reebok Int'1 Ltd. v. K-Mart Corp., 849 F. Supp. 252, 268 (S.D.N.Y. 1994).

$199 I d$. at 268 (noting that "shoes are an item worn daily" that "can lead a customer to experience ongoing discomfort and physical pain," and are thus "much less likely to be the subject of impulse purchases than other low priced consumer goods or consumables").

200412 F.3d 373 (2d Cir. 2005).

201 Id. at 390. 
consumer care. This uninhibited opportunity stands in contrast to the "bustling ... atmosphere of a typical supermarket."202

The Star Industries court's analysis is flawed (or at least incomplete), however, in ways that are illuminated by a broader understanding of the consumer behavior model. Ability is a necessary-but not sufficientcondition for the exercise of consumer care, in that a consumer who has all of the opportunity in the world will not be careful unless she has sufficient motivation to do so. For that reason, without a consideration of the motivation of typical consumers, it cannot reliably be said that

$[\mathrm{u}]$ nhurried consumers in the relaxed environment of the liquor store may be expected to educate themselves sufficiently to recognize the respective brand names, to understand the respective stature of the two companies, and thus to understand how fanciful the notion is that Bacardi would seek the benefit of Star's reputation and good will by entering into a licensing agreement to secure utilization of its " $\mathrm{O}$ " design. ${ }^{203}$

The "unhurried" environment gives liquor purchasers an opportunity "to educate themselves sufficiently" and to be careful enough "to understand" the lack of any association between Bacardi and Star, but that unconstrained ability alone is insufficient. The key question is whether they will have the motivation to do so. They will if they perceive sufficient risk (such as financial or perhaps social risk associated with the liquor purchase), but otherwise, no amount of uninhibited, "unhurried" opportunity will yield this degree of the exercise of consumer care. The elaborate investment in education and care imagined by the Star Industries court is substantial; it seems doubtful that anyone, other than the most motivated (and "unhurried") consumer, would exercise the degree of care hypothesized by the court. ${ }^{204}$ But, at a minimum, the model indicates that opportunity alone is an insufficient basis for a finding of high levels of consumer care or sophistication.

The courts' assumptions about interactions with sales personnel are similarly flawed. It may well be that a consumer who is sufficiently motivated in the purchase of lawn and garden equipment or perfume will exercise even

202 Lever Bros. v. Am. Bakeries Co., 537 F. Supp. 248, 255 (E.D.N.Y. 1982) (concluding that "the ordinary purchaser of AUTUMN margarine and AUTUMN GRAIN bread is a casual, unsophisticated buyer," and also explaining that an atmosphere "in which over 5,000 trademarked items are presented" is unlikely to be conducive to a high level of consumer care).

203 Star Industries, 412 F.3d at 390.

204 Id. 
more care where the "opportunity" for such cognition is facilitated by trained personnel who can be expected to "help[] inform customers of the differences in the products." ${ }^{205}$ But it cannot reliably be said that such opportunity alone ensures high levels of care. The threshold question is whether there is sufficient motivation for consumers to exercise care. For lawn and garden equipment that presents little or no risk (e.g., an inexpensive pair of work gloves), no amount of opportunity will ensure a high degree of consumer care.

\section{b. Compelled "Opportunity" (and Increased Capacity)}

On the other hand, the courts are on stronger theoretical footing in cases where the purchase process requires extended interaction with sales personnel in an inherently complex purchase. In cases involving complex financial instruments or healthcare plans, for example, the consumer behavior model arguably provides some support for the judicial inference of a high degree of consumer care. The reason is that, in those circumstances, the consumer can be presumed to have sufficient motivation (if she proceeds through a complex or multi-step process requiring the exertion of cognition), and the extended opportunity for involvement can only add to the degree of care exercised by the consumer. In other words, where the transaction can proceed only if the consumer proceeds through a complex, multi-step purchase process, we can assume that all consumers who endure this process have sufficient motivation. Since they are sufficiently motivated, the extended opportunity - of frequent exposure over a long period of time-increases the likelihood of exercising a high degree of consumer care. ${ }^{206}$

A complex, multi-step purchase process may also enhance a consumer's "capability" to exercise consumer care. Consumers who have had repeated opportunities to encounter relevant market information will develop more active knowledge structures that will facilitate more efficient and more effective judgment. ${ }^{207}$ Thus, the multi-step purchase process indicates a high

205 Frances Rothschild v. U.S. Cosmetic Fragrance Mktg. Corp., 223 U.S.P.Q. 817, 818 (N.D. Tex. 1983).

206 We are a little less sanguine about the blithe judicial assertion that sales personnel can always be expected to "help[] inform customers" in their performance of the source-identification judgment. Id. Some sales personnel may facilitate source-identification in some circumstances, but that will not always be the case. In some circumstances, the salesperson's motivation will be very different from the consumer's; the former may sometimes give in to the perverse incentive to thwart source identification if that is what it takes to convince the consumer to make the purchase.

207 See supra text accompanying notes 136-37. 
level of consumer care across several levels of the model: motivation is assumed, while opportunity is required. ${ }^{208}$

A similar approach may be the key to understanding a conflict in the case law over the question of whether the "wine buying public" is "a highly discriminating group" 209 or a collection of "generally unsophisticated 'impulse' buyers who are an 'easy mark for a [trademark] infringer.",210 In criticizing the former conclusion (adopted in 1959 by a federal district court in Alabama), the latter court relied on expert testimony to conclude that "the average American consumer is unlearned in the selection of wine."211 The difference in the courts' assessments of the degree of consumer sophistication, however, seems to have more to do with differences in opportunity than with any difference in available evidence of capability. In the Alabama case, there was evidence before the court that state law effectively compelled an extended opportunity to exercise consumer care. ${ }^{212}$ Specifically, as the court explained:

The evidence reflects that practically all of the wine in the State of Alabama is sold through state owned and operated liquor stores. The law requires that the prospective purchaser select from display counters the product he desires, and after making that selection he is required to request that product of the salesman by name. After paying the cashier for the product, it is produced by the salesman for the purchaser's inspection prior to the time it is packaged. Thus, in the State of Alabama it is virtually impossible for a wine purchaser to be confused by similar trademarks. ${ }^{213}$

This is compelled "opportunity." The Alabama wine buyer was effectively required to exercise consumer care through a multi-step exchange with a salesman that involved a request and confirmation of the product name. Such a consumer can be presumed to possess at least enough motivation to complete these steps in order to make the purchase. Thus, and for this reason, the Alabama wine-buying public in 1959 was to some degree a "discriminating

208 We hasten to add two important caveats. First, as explained above, in some circumstances, the steps in a complex purchase process may actually interfere with the source-identification judgment. If sales personnel are motivated to complete the sale, irrespective of any concern about consumer confusion, they mayconsciously or unconsciously - shed more noise than light on the source-identification judgment. Second, and as elaborated below, compelled care will never be the same as care spurred on by a consumer's native involvement. See infra text accompanying note 212.

209 E. \& J. Gallo Winery v. Ben R. Goltsman \& Co., 172 F. Supp. 826, 830 n.2 (M.D. Ala. 1959).

210 E. \& J. Gallo Winery v. Consorzio del Gallo Nero, 782 F. Supp. 457, 465 (N.D. Cal. 1991).

211 Id.

212 See Ben R. Goltsman \& Co., 172 F. Supp. at 830 n.3.

213 Id. 
group," even if the discrimination was not the result of any situational or enduring involvement.

Our model gives ample reason to doubt the court's bolder assertion, however, that it would be "virtually impossible" for such a wine purchaser to be confused. ${ }^{214}$ We see no reason to expect that consumers compelled to engage in an extended purchase process would exercise the degree of care necessary to distinguish between two facially identical trademarks. Indeed, compelled care is an imperfect substitute for care triggered by perceived risk or enduring involvement. A consumer who is compelled to go through the motions of a purchase process will be more likely to just "go through the motions." Thus, although a consumer compelled to participate in extended opportunities for care may be somewhat more careful than one who is not, the compelled consumer is not the equivalent of the consumer whose care is spurred by her own perceptions of risk or her native enduring involvement.

\section{c. Reduced Opportunity}

Finally, if opportunity is conceived of as a necessary prerequisite to consumer care, the consumer behavior model also provides theoretical support for a finding of relatively low levels of consumer care in purchasing environments that reduce opportunities for care. The "infomercial" case cited above arguably fits in here. ${ }^{215}$ To the extent an infomercial requires a hurried, impulsive purchase, a low level of consumer care is indicated despite whatever risk factors might otherwise cue motivation for extended involvement. Similarly, if the "bustling, self-service atmosphere of the typical supermarket" makes it impossible for consumers to engage in careful transactions, ${ }^{216}$ then consumer care is untenable.

Our model suggests good reasons to be skeptical of such a finding, however. Even in the "bustling, self-service atmosphere of the typical supermarket," we might expect a consumer faced with sufficient financial risk - such as in the purchase of a relatively expensive product - to be sufficiently motivated that she might overcome the cacophony of the purchase situation and exercise a relatively high degree of care. Where motivation is

\footnotetext{
214 Id.

215 See supra note 186 and accompanying text (discussing Telebrands Corp. v. E. Mishan \& Sons, 46 U.S.P.Q.2d 1493, 1508 (S.D.N.Y. 1997)).

216 Lever Bros. v. Am. Bakeries Co., 537 F. Supp. 248, 255 (E.D.N.Y. 1982).
} 
high, only the most severe situational constraints on opportunity may effectively foreclose the exercise of consumer care.

Thus, a refinement of the "necessary condition" formulation may be in order: An adequate opportunity is a necessary condition for the exercise of consumer care, but the adequacy of the opportunity will necessarily vary in relation to the level of consumer motivation. Where consumer motivation is high, only the most extreme constraints on opportunity will preclude a finding of consumer care. Where motivation is low, however, even milder constraints, like the cacophonous atmosphere of the supermarket, might foreclose the possibility of the exercise of consumer care.

\section{Frequency of Purchase}

Another factor identified by the courts is frequency of purchase. Infrequently purchased products (such as hand-held vacuum cleaners) are deemed to involve a high degree of consumer care, while frequently purchased items (like disposable diapers or athletic shoes) rate low on consumer care. ${ }^{217}$

Some of these cases merely reformulate the price factor in frequency terms. In Kimberly-Clark Corp. v. H. Douglas Enterprises, Ltd., for example, the Federal Circuit concluded that consumers of disposable diapers exhibit a "'lesser standard of purchasing care"" given that such products "are relatively inexpensive and frequently replaceable.,"218

In other cases, however, the courts appear to assign independent significance to the frequency consideration, as in Black \& Decker, Inc. $v$. North American Philips Corp., where the court determined that a $\$ 20$ to $\$ 40$ hand-held vacuum cleaner is "not the kind of household item that one purchases frequently, but rather is an item that the purchaser expects will last for a lengthy duration and therefore would require care in its purchase", ${ }^{219}$ or

217 Compare Black \& Decker, Inc. v. N. Am. Philips Corp., 632 F. Supp. 185, 193 (D. Conn. 1986) (finding that consumers of hand-held vacuum cleaners are relatively sophisticated in that such a "product is not the kind of household item that one purchases frequently, but rather is an item that the purchaser expects will last for a lengthy duration and therefore would require care in its purchase"), with Kimberly-Clark Corp. v. H. Douglas Enter., Ltd., 774 F.2d 1144, 1146 (Fed. Cir. 1985) (concluding that consumers of disposable diapers exhibit a "lesser standard of purchasing care" given that such products "are relatively inexpensive and frequently replaceable"), and K-Swiss, Inc. v. USA AISIQI Shoes, Inc., 291 F. Supp. 2d 1116, 1125 (C.D. Cal. 2003) ("Athletic shoes are common consumer items and often are purchased several times a year. A reasonable consumer, therefore, is unlikely to exercise a high degree of care in selecting shoes.").

218774 F.2d at 1146.

219632 F. Supp. at 193. 
in K-Swiss, Inc. v. USA AISIQI Shoes, Inc., in which the court concluded that "[a]thletic shoes are common consumer items" that "are purchased several times a year" and thus "unlikely" to involve a "high degree of care.,"220

If there is a theoretical basis in the consumer behavior model for the frequency cases, it is in the motivation element of the involvement construct. Infrequently purchased products may present time risks that enhance the motivation for the exercise of consumer care. Hand-held vacuum cleaners, electric razors, and small appliances, for example, might be relatively inexpensive, but if consumers expect to keep them for a long time, they may have an incentive to process their purchase more deeply than they would for items they expect to replace more often. Compare the hand-held vacuum in Black \& Decker with the athletic shoes in $K$-Swiss. If the vacuum is likely to be retained for a long period of time, its purchase will arouse performance concerns not implicated by a comparably priced—but oft-replaced-pair of athletic shoes. For that reason, the hand-held vacuum consumer in Black \& Decker may be more highly motivated than the athletic shoe buyer in $K$-Swiss.

Yet the model does not provide unequivocal support for these frequency cases. For one thing, an infrequent purchase will not always correspond with a long duration of ownership and, therefore, high time risk. Certain specialoccasion purchases - for example, Halloween-themed candy to be given to trick-or-treaters - will be purchased infrequently, but will present little time risk in the sense that the products are not durable and will not be consumed for long periods of time. For those items, the consumer behavior model does not predict an increase in consumer care.

More fundamentally, involvement is only half of the story of exercised consumer care. The opportunity factor must also be evaluated, and on that factor, frequency of purchase often cuts the other way. First, frequency of purchase enhances the opportunity for consumer care. With more frequent purchase comes increased exposure to information, and increased exposure facilitates the opportunity to exercise consumer care. Second, frequency may also enhance consumer capability, in that the repeat consumer may develop more elaborate knowledge structures that will enhance both the efficiency and the accuracy of her judgment.

Return again to the comparison between the Black \& Decker and K-Swiss cases. Even if the vacuum buyer is more highly motivated than the shoe 
purchaser, ${ }^{221}$ the latter may ultimately be more "careful"-in the sense of having more extensive opportunity for care and in being more efficient and accurate in exercising judgment. Over the course of numerous shoe purchases, the consumer will be exposed repeatedly to advertisements and promotional information of relevance to the purchase. Those expanded opportunities, moreover, may translate into greater consumer capacity, since the shoe buyer's previous experience with and knowledge of the product category will facilitate the acquisition of new information about shoes - increasing both the efficiency and the accuracy of her judgment.

Our model does not pretend to provide a basis for measuring the comparative significance of these competing considerations. Thus, the model cannot compare the motivation-enhancing effects of infrequent purchases with the opportunity- and capability-enhancing effects of frequent purchases. Importantly, however, the model does provide a theoretical basis for questioning the courts' monotonic assessment of the frequency of purchase factor. This factor may ultimately be a wash, and at a minimum, the courts should be careful not to assign too much weight to it.

\section{Professional Buyers and Avid Hobbyists}

Courts consistently presume that professional buyers are sophisticated (higher in motivation and ability) and thus exercise a high degree of care in product categories within their area of expertise or responsibility. ${ }^{222}$ In Oreck Corp. v. U.S. Floor Systems, Inc., ${ }^{223}$ for example, the Fifth Circuit considered a trademark infringement claim by Oreck against a competitor in the carpetcleaning industry. ${ }^{224}$ One of Oreck's claims focused on professional-grade cleaning machines that were used only by service contractors, professional

221 There may be reason to doubt that conclusion too-particularly once the motivation analysis looks beyond financial and time risks to consider social risk. For many consumers, shoes present significant levels of perceived social risk. To the extent the consumer worries that her peers will judge her by the brand of shoes she wears - that her shoes say something about her at the gym, in the office, or in social settings- that consumer may be highly motivated to exercise care. If the motivation from this perceived social risk outweighs the motivation stemming from perceived time risk in the purchase of the small appliance, the shoe purchaser may be even more motivated than the small appliance buyer.

222 See, e.g., Moore Bus. Forms, Inc. v. Rite Aid Corp., 210 U.S.P.Q.2d 2024, 2029 (W.D.N.Y. 1991), modified, 1992 WL 125561 (W.D.N.Y. May 29, 1992), aff'd, 983 F.2d 1048 (2d Cir. 1992) (declaring that business executives are simply more sophisticated in many areas); HQ Network Sys. v. Executive Headquarters, 755 F. Supp. 1110, 1119 (D. Mass. 1991) (holding that business executives are generally more sophisticated in all areas).

223803 F.2d 166 (5th Cir. 1986).

224 Id. at $167-68$. 
carpet-cleaning services, and building maintenance managers. ${ }^{225}$ Because these purchasers are directly responsible for carpet care and are in charge of buying for professional and institutional purchases, the court concluded that they are "informed, deliberative buyers" who are unlikely to be confused. ${ }^{226}$ As one court put it, professional buyers are easily distinguishable from the prototypical case "involving the spending of discretionary income on the primary basis of slick brochures and fancy advertising.,"227

In some cases, the courts have adopted a presumption of sophistication for products consumed by professional buyers. ${ }^{228}$ In Trustees of Columbia University v. Columbia/HCA Healthcare Corp. ${ }^{229}$ for example, the district court found that "purchasers of medical and healthcare services provided by hospitals" are sophisticated professionals. ${ }^{230}$ "[A]lthough members of the general public are the technical purchasers of medical and healthcare services provided by hospitals," the court found that "the real purchasers for the purposes of trademark analysis are the doctors who choose the hospitals to which they send their patients," and that "doctors generally are a very sophisticated group of consumers who use great care in deciding which hospitals with which to affiliate themselves and to which they send their patients. ${ }^{231}$ Additional examples of cases adopting this presumption are those involving cross-view school bus mirrors ${ }^{232}$ and commercial-grade zippers sold for use in other products. ${ }^{233}$

225 See id. at 173.

226 Id.

227 HQ Network Systems, 755 F. Supp. at 1119.

228 Compare, e.g., Racemark Int'l v. Specialty Prods., Inc., 217 U.S.P.Q. 772, 780 (N.D.N.Y. 1982) (finding no likelihood of confusion from the use of RACEMARK and ROSSMARK as trademarks for car floor mats where they are sold in large quantities to sophisticated purchasing agents for original equipment automobile manufacturers and large chains of retail stores), with, e.g., Rail-Track Constr. Co. v. Railtrack, Inc., 218 U.S.P.Q. 567, 571 (T.T.A.B. 1983) (even highly sophisticated, technically trained purchasers may be confused when almost identical marks-RAIL-TRACK and RAILTRACK - are used in same general field of trade).

229964 F. Supp. 733 (S.D.N.Y. 1997).

230 Id. at $748-49$.

231 Id.

232 See Rosco, Inc. v. Mirror Lite Co., 139 F. Supp. 2d 287, 299 (E.D.N.Y. 2001), aff'd in part, rev'd in part, and remanded, 304 F.3d 1373 (Fed. Cir. 2002) (relying on sophistication of purchasers in the school bus mirror market to sustain a finding of unlikelihood of confusion).

233 YKK Corp. v. Jungwoo Zipper Co., 213 F. Supp. 2d 1195, 1205 (C.D. Cal. 2002) (noting that plaintiff "YKK sells its [zippers and fasteners] to the following categories of consumers: (1) name-brand and privatelabel clothing manufacturers (e.g., Levi Strauss and The Gap); (2) the makers of other products ranging from wetsuits to sleeping bags; (3) 'assemblers' who buy and assemble zipper components; and (4) 'jobbers' who act as distributors"). 
Avid hobbyists are also often presumed to exercise a high degree of care in distinguishing trademarks of products that fall within their areas of interest. ${ }^{234}$ In Sunenblick v. Harrell, ${ }^{235}$ the plaintiff attempted to prove a likelihood of confusion between two record labels. ${ }^{236}$ The plaintiff's record label focused its work on jazz music, while the defendant's label focused on rap and hip-hop music. ${ }^{237}$ The court held that most music purchasers are highly sophisticated in distinguishing between two very different genres of music. ${ }^{238}$ Similarly, many courts have held that investors are sophisticated purchasers because of their extensive involvement in the industry. ${ }^{239}$

The enduring involvement and ability elements of the consumer behavior model provide theoretical support for this line of cases - as well as a limiting principle and admonition against assigning talismanic significance to this factor.

\section{Enduring Involvement and Enhanced Capability}

Professional buyers and avid hobbyists may be seen as consumers with enduring involvement-individuals who are predisposed to experience heightened arousal or "felt" involvement in a given context where the object of that enduring involvement is concerned. ${ }^{240}$ Due to their ongoing interest and concern with a product, moreover, these consumers can be expected to develop expertise and extended knowledge structures for that product category, which they can then draw upon during specific episodes, such as information search,

234 See, e.g., Interstellar Starship Servs. v. Epix, Inc., 125 F. Supp. 2d 1269, 1277-78 (D. Or. 2001)

(holding that hobbyists are grouped into the category of "expert" buyers for sophistication purposes).

235895 F. Supp. 616 (S.D.N.Y. 1995).

236 Id. at 619-20.

237 Id. at 634.

238 See id. (holding that "customers of musical recordings are necessarily discriminating as between jazz and hip-hop, and are not likely to suffer confusion in the same manner as customers who might purchase less easily differentiated goods bearing confusingly similar trademarks").

239 See, e.g., Altira Group LLC v. Philip Morris Co., 207 F. Supp. 2d 1193, 1202-03 (D. Colo. 2002) (characterizing SEC accredited individuals as sophisticated consumers); Haven Capital Mgmt., Inc. v. Havens Advisors, L.L.C., 965 F. Supp. 528, 531 (S.D.N.Y. 1997) (stating investors who put large amounts of money into high risk investments know the brokers they deal with and are unlikely to be confused); McGraw-Hill, Inc. v. Comstock Partners, Inc., 743 F. Supp. 1029, 1036 (S.D.N.Y. 1990) (finding that investors and managers of large funds too sophisticated to confuse investment management service with investment data transmission service). But see Towers v. Advent Software, Inc., 17 U.S.P.Q.2d 1471, 1473 (T.T.A.B. 1989), aff'd, 913 F.2d 942 (Fed. Cir. 1990) (finding PROFESSION PORTFOLIO confusingly similar to THE PROFESSIONAL PORTFOLIO SYSTEM even though customers are sophisticated investment professionals).

240 Robin A. Higie \& Lawrence F. Feick, Enduring Involvement: Conceptual and Measurement Issues, in 16 AdVANCES In CONSUMER RESEARCH 690, 690 (Thomas K. Srull ed., 1989). 
product evaluation, and product purchase. ${ }^{241}$ Given the resource of these more extensive knowledge structures and the greater personal salience of the product category, these consumers will, in general, be facilitated in their search sophistication when parsing details and differences between brands. Overall, and in general resonance with the courts' view, these consumers should be less likely to become confused.

As with other factors relevant to the degree of consumer care, however, the buyer's vocational or avocational interest in the transaction should not be considered in isolation. In some circumstances, the enhanced capability and enduring involvement of the professional or hobbyist consumer will be augmented by other factors in the cognition function. For some such consumers, for example, situational involvement and opportunity elements will further contribute to the degree of consumer care.

Consider the case of Astra Pharmaceutical Products, Inc. v. Beckman Instruments, Inc. ${ }^{242}$ in which the plaintiff sought to enjoin the defendant's use of the ASTRA trademark on its computerized blood analyzer machine. ${ }^{243}$ The starting point for the court's analysis of the degree of consumer care was the assertion that the relevant buyer class consisted of "hospital chemistry labs" and the "pathologist," "chemist," and "chief laboratory technologist" employed in those labs. ${ }^{244}$ That fact alone implicates some degree of enduring involvement and increased capacity, which in turn would indicate relatively high levels of care (all other things being equal).

But in the Astra case, these indicators of the exercise of consumer care would merely be augmented by other factors. First is the motivation for situational involvement engendered by financial and performance risks: The purchase of "a machine worth thousands of dollars is obviously not done on an impulse, and involves a careful consideration of the reliability and dependability of the manufacturer and seller of the product." 245 In addition, the purchase transaction for the ASTRA machine involved compelled

241 Glenn L. Christensen \& Jerry C. Olson, Involved with What? The Impact of Heterogeneity in Goal Hierarchies on High Enduring Involvement, in 28 ADVANCES IN CONSUMER RESEARCH 392, 393 (Mary C. Gilly \& Joan Meyers-Levy eds., 2000) (describing the developing and evolving knowledge structures of highly involved consumers); see also Joseph W Alba \& J. Wesley Hutchinson, Dimensions of Consumer Expertise, 13 J. CONSUMER RES. 411, 415 (1987) (analyzing the extensive knowledge structures of experts and the facilitative effects those structures enable).

242718 F.2d 1201 (1st Cir. 1983).

243 Id. at $1203-04$.

244 Id. at 1206.

245 Id. 
opportunity for care: "It takes from three months to a year to consummate the sale of a[n analyzer], involving an average of 55 hours of personal contact between lab personnel and sales representatives." ${ }^{246}$ Thus, in some circumstances, as in the Astra case, the usual presumption of a high level of care for professional buyers will be enhanced by other factors.

The presumption may not hold in other cases, however. Although professional buyers will be predisposed to heightened enduring involvement in purchases falling within the ambit of their interests, that predisposition would not extend equally across all such purchases. If the laboratory technologist in Astra is also involved in purchasing bathroom supplies for the hospital, for example, he should not be expected to exercise the same level of care for those purchases as he would with respect to the purchase of the blood analyzer. In one sense, the technologist is the same "professional," "sophisticated" person, regardless of the nature of the transaction. But as our model indicates, the relevant inquiry should focus on the technologist's motivation and opportunity for care under the circumstances, not on his level of professional training or expertise in the abstract. And with respect to bathroom supplies, the technologist would perceive only minimal financial and performance risk and would possess little, if any, capability advantages or compelled opportunities for extended involvement.

A similar line of analysis provides a possible ground for resolving a conflict in the case law over the degree of care exercised in the alcoholic beverage market. Although beer buyers have long been thought to act on impulse, ${ }^{247}$ one court famously asserted that crème de menthe liquor purchasers would exercise "a greater degree of sophistication and care than might be true in their purchase of other merchandise." 248 Professor McCarthy finds it "impossible" to reconcile these cases, "except on the unjustified assumption that crème de menthe is a sophisticated drink, while beer is mundane. $" 249$ In contrast, our model provides a framework for moving beyond stereotypes about the relative sophistication of these products and (perhaps) for reconciling the cases.

246 Id.

247 See, e.g., Miller Brewing Co. v. G. Heileman Brewing Co., 427 F. Supp. 1192, 1197 (W.D. Wis. 1977).

248 Societe Anonyme, Etc. v. Julius Wile Sons \& Co., 161 F. Supp. 545, 548 (S.D.N.Y. 1958).

249 MCCARTHY, supra note 2, § 23:99. 
The key question is whether crème de menthe purchasers may be expected to have greater motivation or greater opportunity than a beer buyer, or both. In the crème de menthe case, the court proffered one basis for conceptualizing this distinction: Crème de menthe "generally involves an exercise of personal taste" that is different from that implicated by the purchase of a "mass produced low priced article[]" such as beer. ${ }^{250}$ Crème de menthe, in other words, may be a specialty item aimed at a niche market composed of enduringly involved consumers with a high degree of capability for cognition. As a "mass produced" article, beer is not. ${ }^{251}$ Thus, even holding prices (and thus financial risk) equal, the crème de menthe purchaser may be more likely to exercise consumer care for reasons that have to do with the assumed target market for these products and not with whether one is inherently more "sophisticated" and the other "mundane.",252

\section{Contextual Limitations on Enduring Involvement and Capability}

While the involvement and capability presumed to be possessed by the professional buyer or avid hobbyist is facilitative, it is also circumscribed and contextual. Professional buyers may be expected to have more capability in their exercise of care for work-related purchases, and avid hobbyists can be assumed to be more capable within the ambit of their hobby. But the facilitative effects of this knowledge would be dramatically attenuated in areas outside of these buyers' expertise.

For this reason, the courts have overplayed their hand in asserting that business executives are generally sophisticated merely "by virtue of their substantial business experience and advanced academic degrees.. ${ }^{, 53}$ Such analysis conflates two distinct sub-elements of opportunity: previous knowledge (a capability attribute) and educational attainment (a capacity attribute). An "advanced academic degree" is an indication-perhaps a weak

250 Society Anonyme, Etc., 161 F. Supp. at 547-48.

251 See, e.g., In re Bercut-Vandervoort \& Co., 229 U.S.P.Q. 763, 765 (T.T.A.B. 1986) (distinguishing wine from crème de menthe cordials and explaining that wine is a "commonly purchased product" that is "purchased by ordinary adult consumers for a variety of reasons, such as for parties, to drink as an accompaniment to a meal and the like").

252 We cannot pretend to know whether the niche market or enduring involvement label properly applies to crème de menthe liquor. But if there is a proper ground for reconciling these cases, it is on this basis, and future litigation in this area should focus on this question and not on some inherent "quality" of the product category - a course already charted in some of the recent cases. See Palm Bay Imps., Inc. v. Veuve Clicquot Ponsardin Maison Fondee En 1772, 396 F.3d 1369, 1376 (Fed. Cir. 2005) (concluding that champagne and sparkling wines are purchased by "general consumers, not just connoisseurs").

253 Beneficial Corp. v. Beneficial Capital Corp., 529 F. Supp. 445, 449-50 (S.D.N.Y. 1982). 
one - of enhanced capacity (computer "hardware," to recall the analogy above $^{254}$ ) resulting from the processing skills, strategies, methods, and experience gained through education. "Business experience," however, goes to capability ("software") derived from the increased knowledge structures acquired on the job. The advanced degree might give a general assurance of enhanced opportunity across the board, but "business experience" would not. Experience would facilitate careful processing only if the knowledge gained from that experience is relevant to the information processing at hand. In short, highly educated, experienced business executives may lack motivation and ability in some of their purchases; there is no reason to expect such consumers to be more careful across the board.

Consider the doctor consumers in the Columbia/HCA Healthcare case. ${ }^{255}$ Their education provides some general indication of their capacity for exercising consumer care across all purchases. But their experience in "deciding which hospitals with which to affiliate themselves and to which they send their patients" ${ }^{\prime 256}$ is highly circumscribed and contextual. That "expertise" or "sophistication" would therefore be irrelevant in a trademark infringement case arising outside of the hospital setting.

The more general caveat mentioned above also bears repeating here: It is likely that there are situations where the consumer's professional interest in the product and more developed knowledge structures may lead her to become more confused. In other words, high enduring involvement may not be unidirectional or monotonic in reducing the likelihood of confusion. A professional buyer, for example, might be more likely to assume a connection between a junior and senior trademark in a new, brand-extended market. Consider the $Y K K$ zipper case ${ }^{257}$ mentioned above. A professional zipper buyer would be more familiar with the YKK brand than a typical retail purchaser and, thus, might be more likely to be confused by an unauthorized junior use of the YKK name in connection with fabrics or materials used by the clothing, wetsuit, and sleeping bag manufacturers who buy YKK zippers. Since enduring involvement can be expected to cue a false connection that might not occur to less "sophisticated" consumers, and the exercise of consumer care may not dispel that connection in the case of an apparently

\footnotetext{
254 See supra text accompanying notes 124-28.

964 F. Supp. 733 (S.D.N.Y. 1997).

Id. at $748-49$.

YKK Corp. v. Jungwoo Zipper Co., 213 F. Supp. $2 d 1195$ (C.D. Cal. 2002).
} 
identical junior use, ${ }^{258}$ the "careful," "sophisticated" consumer is the one most likely to be confused in this context.

\section{E. Education, Income, Age, Gender}

The courts have also identified some secondary considerations that are thought to correlate with consumer care or sophistication. Among the considerations identified by the courts are education, income, age, and gender. On some points, this line of cases finds some general support in the consumer behavior model. Again, however, the case law is plagued by overgeneralizations that could be avoided by a more complete understanding of the determinants of the exercise of consumer care during the sourceidentification judgment.

\section{Education}

In cases where the target consumer is seen as highly educated, the courts consistently presume that consumer care is high. ${ }^{259}$ Although the basis for the presumption is seldom explored in any detail, the courts routinely find a high degree of sophistication where the typical consumer has a "college education[]," ${ }^{, 60}$ is "well educated,",261 or even is "undoubtedly literate.",262

These conclusions find general support in the consumer behavior literature. Formal education has been shown to improve capacity for careful processing by improving a consumer's processing strategies, problem-solving skills, and ability to parse complex information. ${ }^{263}$ Thus, as the consumer's level of education increases, so too should her opportunity to exercise consumer care.

258 See, e.g., In re New Archery Products Corp., 218 U.S.P.Q. 670, 672 (T.T.A.B. 1983) (finding that purchasers of fishing and hunting equipment are apt to be discriminating purchasers, but nevertheless could be confused as to the connection between RAZORBACK 5 as a mark for arrowheads and RAZORBACK for fishing lures).

259 See, e.g., WE Media, Inc. v. Cablevision Sys. Corp., 94 F. App'x. 29, 32 (2d Cir. 2004) (finding targeted audience of women with college education less likely to be confused); Girl Scouts of U.S. v. Bantam Doubleday Dell Publ'g Group, Inc., 808 F. Supp. 1112, 1130 (S.D.N.Y. 1992) (noting that purchasers of children's books are "undoubtedly literate" and "not necessarily "unsophisticated" despite the low price of the books); Inc. Publ'g Corp. v. Manhattan Magazine, Inc., 616 F. Supp. 370, 381 (S.D.N.Y. 1985) (finding that consumers of business magazines were sophisticated where "demographic studies in evidence show that readers ... tend to be well educated, affluent, and commercially successful").

260 WE Media, 94 F. App'x at 32.

261 Inc. Publ'g Corp., 616 F. Supp. at 381.

262 Girl Scouts of U.S., 808 F. Supp. at 1130.

263 Jutta Heckhausen \& Carol S. Dweck, Motivation and Self-Regulation Across the Life SPAN 258 (1998). 
But that does not mean that the highly educated consumer will always be careful or sophisticated. Enhanced opportunity is only one element of our model of consumer care - an element that by itself is insufficient to predict the level of care that will be exercised by consumers. Even a highly educated (and thus adeptly capable) consumer will not engage in careful processing in all of her decisions. There must also be some motivation as a necessary condition for consumer care.

Some of the above-cited cases fail to acknowledge this important nuance. Consider the case of Girl Scouts of the United States v. Bantam Doubleday Dell Publishing Group. ${ }^{264}$ The plaintiff in that case (the Girl Scouts) challenged the defendant's sale of a line of children's books bearing the title "Pee Wee Scouts." $" 265$ In the course of granting the defendant's motion for summary judgment, the court rejected the plaintiff's argument that purchasers of the defendant's low-priced books were unsophisticated. ${ }^{266}$ Although the court acknowledged that books ranging in price from $\$ 2.50$ to $\$ 2.75$ "might be categorized as 'impulse' buys," it nonetheless found that defendant's consumers "are not necessarily "unsophisticated," since "purchasers of children's books are undoubtedly literate," and "undoubtedly they have in mind supplying quality reading material to a five or six year old.,

Literacy and education are not sufficient conditions for the exercise of consumer care in and of themselves. Unless the buyer of a low-priced children's book has some degree of motivation to investigate the source of the book, no amount of literacy or education should be expected to diminish the likelihood of confusion. Indeed, in the Girl Scouts case, the consumer's supposed goal of "supplying quality reading material" ${ }^{\text {"268 }}$ might, if anything, increase the likelihood of sponsorship confusion where (1) the Girl Scouts trademark has acquired goodwill and a reputation for quality; and (2) the book title's name on its face suggests some connection with the Girl Scouts. In the absence of financial risk or any other significant motivation for exercising consumer care, the "literate" consumer's supposed enhanced capacity is by no means a guarantee of a high level of care.

264808 F. Supp. 1112.

$265 I d$. at $1114-16$.

266 Id. at $1129-30$.

267 Id.

268 Id. 
The district court's decision in Inc. Publishing Corp. v. Manhattan Magazine, Inc. ${ }^{269}$ is similarly flawed. In that case, the court found that purchasers of business magazines were "sophisticated," given that "readers who subscribe to [such] magazines are successful, educated, relatively affluent, business or profession-oriented people." ${ }^{270}$ Such demographic evidence goes only to capacity; if there are no risk factors sufficient to engender motivation (since magazines are low-priced impulse products), there is no reason to anticipate a high degree of consumer care in the purchase of the magazineeven if the magazine's readers might generally be seen as "sophisticated."

This is not to say that the courts necessarily erred in finding in favor of the defendants in the Girl Scouts or Inc. Publishing cases. It may well be that the likelihood of confusion was insufficient in those cases to support a judgment for the plaintiffs. But if that is the right outcome, it is because other factors in the likelihood of confusion calculus outweigh the low degree of consumer care-not because consumer care is high. In the Inc. Publishing case, for example, the court found that the title and logo of the defendant's magazine ("Manhattan, inc., The Business of New York") was sufficiently different from the plaintiff's ("Inc., The Magazine for Growing Companies") to sustain a finding that confusion was unlikely. ${ }^{271}$ And in the Girl Scouts case, the court found that "there [was] little similarity between Defendants' books" - which were about "a fictional entity with a name different from those of Plaintiffs' organizations"- and the Girl Scouts' trademarks. ${ }^{272}$ Those findings seem sensible (and probably correct), but that does not justify the courts' makeweight assessment of the degree of consumer care where that assessment is not sustainable on its own merits and may distort the development of the law in future cases.

\section{Income}

Occasionally, the courts have also suggested a connection between sophistication and income or wealth. The Southern District of New York has sometimes adverted to the notion that consumers "from low income groups" may be "less sophisticated shoppers than wealthier purchasers."

269616 F. Supp. 370 (S.D.N.Y. 1985).

$270 I d$. at 396.

271 Id. at $380-81$.

272808 F. Supp. at 1124.

273 Schieffelin \& Co. v. Jack Co. of Boca, 850 F. Supp. 232, 250 (S.D.N.Y. 1994); see also Citibank, N.A. v. Citytrust, 596 F. Supp. 369, 373 (E.D.N.Y. 1984) (identifying an instance of actual confusion in the record 
the case law is hardly uniform on this point, and more recent decisions seem to point in precisely the opposite direction.

In the Schieffelin \& Co. v. Jack Co. of Boca, the Southern District of New York acknowledged that consumers of the defendant's DOM POPINGNON popcorn, sold in champagne bottles bearing labels resembling the plaintiff's DOM PERIGNON mark, were unsophisticated, low-income consumers. ${ }^{274}$ Similarly, in Planned Parenthood v. Bucci, ${ }^{275}$ the same court conceded that the target consumers for Planned Parenthood's services were "low income, relatively unsophisticated women." ${ }^{276}$ Although the court in both cases ultimately found that even these low-income consumers could be thought to exercise a degree of care under the specific circumstances presented, the court did not question the general premise that consumer care rises and falls with wealth or income. ${ }^{277}$

The same court was a little more skeptical about the import of consumer wealth in Reebok International Ltd. v. K-Mart Corp. ${ }^{278}$ In that case, Reebok accused K-Mart of infringing its trademarks and trade dress in the sale of KMart's low-priced TITAN athletic shoes, asserting (among other things) that the budget-minded K-Mart consumer was unsophisticated. ${ }^{279}$ The court distanced itself in part from the above-quoted pronouncements on wealth and sophistication, finding a lack of support in the evidence for the proposition "that the K-Mart customer is necessarily unsophisticated." $" 280$ In the Reebok court's view, it is "more than a little elitist to believe that K-Mart shoppers fail to exercise care merely because they shop at a discount store," and it may even

and noting that such consumer "might fairly be characterized as sophisticated if there is a correlation between accumulation of wealth and sophistication").

274850 F. Supp. at 250.

27542 U.S.P.Q.2d 1430 (S.D.N.Y. 1997).

276 Id. at 1439.

277 In Schieffelin, the court found that a buyer of defendant's product likely would do so only "after viewing the bottle carefully, grasping the joke, and seeking to share it with others." $850 \mathrm{~F}$. Supp. at 250 . In Planned Parenthood, the court found that although Planned Parenthood's low-income consumers were generally unsophisticated, the target sub-group at issue in the case had "Internet access," and thus could be thought to be "more sophisticated." 42 U.S.P.Q.2d at 1439. Ultimately, however, the Planned Parenthood court found that the consumers in question "may not be so immediately perspicacious" as to the fact that the registrant of the plannedparenthood.com domain name was not Planned Parenthood, but a radio talk show host attempting to advance an anti-abortion message. Id. at 1439.

278849 F. Supp. 252 (S.D.N.Y. 1994).

279 Id. at 268 .

280 Id. 
be the case that "shoppers with limited budgets use more care in spending their more limited resources than shoppers at non-discount stores."281

In response to the Schieffelin court's conclusions regarding the DOM PERIGNON trademark, the Reebok court conceded that "low income purchasers might have less familiarity with purchase of a super-luxury item such as a $\$ 100$ bottle of champagne than would wealthy consumers," but otherwise expressed its disagreement with the "implication that there is a direct relationship between income and consumer intelligence." ${ }^{282}$ Thus, the Reebok court pointedly concluded that "[c]areless shopping habits are not a necessary by-product of low income." 283

Our model suggests that income and wealth are poor predictors of the exercise of consumer care. Unless income or wealth affects motivation or opportunity, there is no theoretical basis for expecting a positive correlation with the degree of consumer care. We see no a priori reason to find a positive relationship between income or wealth, on one hand, and motivation or opportunity, on the other, and thus, no basis for adopting the presumption that "low income groups" are "less sophisticated shoppers than wealthier purchasers. $" 284$

With respect to motivation, the Reebok court's opposite presumption finds some degree of support in our model. A low-income consumer may perceive relatively higher financial risk in a given purchase than her wealthier counterpart. Indeed, the low-income consumer's increased financial risk might even be exacerbated by increased performance or time risk-because, for example, a low-income consumer has less experience with a product category or expects to replace the product less frequently. Consider the DOM PERIGNON example addressed by the Reebok court. ${ }^{285}$ The low-income

281 Compare id. with Crain Commc'ns, Inc. v. Fairchild Publ'ns, Inc., 12 U.S.P.Q.2d 1214, 1216 (E.D. Mich. 1989) (asserting that "intelligence insures neither accurate perception nor care in purchasing," and that "[i]n fact, intelligent wealthier consumers may be more inclined to impulse purchasing because the price is insignificant").

282849 F. Supp. at 268 n. 18.

283 Id.

284 Schieffelin \& Co. v. Jack Co. of Boca, 850 F. Supp. 232, 250 (S.D.N.Y. 1994); see also Telemed Corp. v. Tel-Med, Inc., 588 F.2d 213, 220 (7th Cir. 1978) ("Defendants gear their program not to the discriminating professional but rather to the public in general, especially those members in the lower income, less sophisticated 'market."'); Citibank, N.A. v. Citytrust, 596 F. Supp. 369, 373 (E.D.N.Y. 1984) (identifying an instance of actual confusion in the record and noting that such consumer "might fairly be characterized as sophisticated if there is a correlation between accumulation of wealth and sophistication").

285849 F. Supp. at 268 n. 18. 
consumer may perceive relatively greater financial risk since a $\$ 100$ purchase may have a greater impact on her bottom line. The same consumer may also perceive heightened performance risk, since she may have less experience and expertise in purchasing \$100 champagne. ${ }^{286}$ For these reasons, the low-income consumer may be more highly motivated to exercise consumer care, all other things being equal. ${ }^{287}$

That leaves the question of opportunity. To our knowledge, there is no support in the consumer behavior literature for any necessary connection between capacity or capability and income or wealth. In fact, research findings suggest that income is unrelated to a "need for cognition."288

That is not to say that that neither income nor wealth could ever be shown to correlate meaningfully with opportunity. In certain circumstances, a target group of wealthy consumers might be expected to exhibit a high level of capacity for careful processing where the wealthy consumers are also highly trained or educated. Alternatively, a wealthy clientele might be shown in a certain case to have relatively greater experience with certain purchases, and that fact could likewise be deemed to translate into increased capacity. ${ }^{289}$ The DOM PERIGNON champagne example fits in well here. ${ }^{290}$ If consumers of $\$ 100$ champagne have relatively greater experience in such purchases, they may have acquired more effective knowledge structures for processing the information necessary to make an informed purchase. Specifically, wealthier

286 In this sense, the Reebok court's acknowledgement that "low income purchasers might have less familiarity with purchase of a super-luxury item such as a $\$ 100$ bottle of champagne," id., serves only to further undermine the presumption of a positive correlation between income/wealth and consumer care. Since a lack of purchase experience can trigger an increased perception of performance risk, the inexperienced lowincome consumer may be even more highly motivated to engage in extended cognition. For reasons explained below, however, inexperience may cut in the opposite direction when it comes to the opportunity construct. See infra text accompanying notes 288-89.

287 Continuing the champagne example, there is one risk factor that conceivably could be thought to correlate positively with wealth/income: social risk. See Schieffelin \& Co., 850 F. Supp. at 250. If it could be shown that wealthy consumers are more likely to be motivated by a concern that they may be judged socially by the champagne that they purchase, then this factor could militate back in favor of finding greater motivation for care by higher-income consumers. See id. Although that possibility should be evaluated in the specific circumstances of an individual case, it is hardly support for a general presumption of increased care by wealthy purchasers.

288 Cacioppo et al., supra note 90, at 217.

289 Thus, the consumer's relative level of experience cuts in opposite directions under our model: a lack of experience may fuel greater motivation in response to an increased performance risk in the face of uncertainty, but at the same time the highly motivated, inexperienced consumer may be relatively less capable of engaging in extended cognition.

290 See Schieffelin \& Co., 850 F. Supp. at 250. 
consumers may be more familiar with the appearance of the genuine article, and they may thus have greater capacity for distinguishing imitations.

Ultimately, these points underscore the need to evaluate capacity and capability directly, without consideration of consumer income or wealth. The target class of consumers may well possess an enhanced opportunity for careful processing, but that opportunity would stem not from their income or wealth, but from their education or experience. And in any event, any enhanced opportunity would be an inadequate condition by itself for the exercise of consumer care; motivation is a necessary precondition for consumer care, and the wealthy consumer is, if anything, less motivated to be careful.

\section{Age}

The courts have frequently assumed a positive correlation between age and consumer care. Older consumers are generally thought to be sophisticated, ${ }^{291}$ while younger consumers are conceived as relatively careless. ${ }^{292}$ Thus, in a series of cases, the courts have found that where "children are 'the ultimate consumers' of a product, they 'are not likely sophisticated enough to differentiate between . . . two different manufacturers." 293 Such cases include those involving trading cards, ${ }^{294}$ magazines, ${ }^{295}$ pop music records, ${ }^{296}$ and clothing. ${ }^{297}$

291 See, e.g., Banfi Prods. Corp. v. Kendall-Jackson Winery, Ltd., 74 F. Supp. 2d 188, 199 (E.D.N.Y. 1999) (finding consumers of wine, who are likely to be older than the general population, to be relatively sophisticated).

292 See, e.g., Blake Publ'g Corp. v. O’Quinn Studios, Inc., 202 U.S.P.Q. 848, 858 (S.D.N.Y. 1979).

293 Chrysler Corp. v. Newfield Publ'ns, Inc., 880 F. Supp. 504, 510 (E.D. Mich. 1995) (quoting Educ. Testing Serv. v. Touchstone, 739 F. Supp. 847, 853 (S.D.N.Y. 1990)).

294 See Chrysler Corp., 880 F. Supp. at 511 (concluding that "young boys between the ages of 8 and 14," the target market for defendant's automobile trading cards, are "not sophisticated enough to differentiate between [defendant's cards and those] licensed by Plaintiffs").

295 See Blake Publ'g, 202 U.S.P.Q. at 858 (finding a lack of sophistication in a market involving magazines aimed at young teens, asserting that "[c]hildren under $16 \ldots$ are not likely to bring a great deal of care and sophistication to their purchasing decisions").

296 See Gen. Foods Corp. v. Mellis, 203 U.S.P.Q. 261, 263 (S.D.N.Y. 1979) (concluding that consumers of pop music records, sold under the title "I'm the Pop Rock King" and marketed along with a package of plaintiff's Pop Rocks candy, were unsophisticated since the "consuming universe to which the products are directed is that of children").

297 See Toys 'R' Us, Inc. v. Canarsie Kiddie Shop, Inc., 559 F. Supp. 1189, 1199 (E.D.N.Y. 1983) (finding that ultimate consumers of children's clothing are children, who are presumed to be unsophisticated). 
Toys ' $R$ ' Us, Inc. v. Canarsie Kiddie Shop, Inc. ${ }^{298}$ demonstrates the courts' willingness to assume that younger consumers are careless. In this case, the court had to decide whether the defendant's use of the KIDS ' $R$ ' US mark in selling "moderately priced clothing articles" was in competition with the plaintiff's TOYS ' $R$ ' US mark. ${ }^{299}$ In the course of finding a sufficient likelihood of confusion among an appreciable number of consumers, the district court adverted to the notion of a "common, if not nagging, experience of parenthood" involving "the coercion of children that their clothing be of a current style and purchased in a designated place. ${ }^{, 300}$ In the court's view, such "vigorous promptings of children to which parents not infrequently succumb make the children, in reality, the true purchasers," resulting in a "lowering of the level of sophistication. $\$ 301$

At least one court has questioned the notion of the careless child consumer. In E.S. Originals, Inc. v. Stride Rite Corp. ${ }^{302}$ the court found a relatively high level of sophistication among the ultimate consumers of children's athletic shoes. ${ }^{303}$ While acknowledging "case authority to the effect that children's coercive requests must be considered in evaluating the sophistication of the purchaser of certain children's goods, ${ }^{, 304}$ the court nonetheless rejected the proposition that "sophistication of the purchaser is necessarily diminished because the product is targeted to children." ${ }^{, 305}$ Specifically, the court suggested that "[a] child carefully programmed by an effective advertising campaign" may be the consumer that is "most likely to insist on the advertised product and is not likely to accept a substitute," and concluded that "the sophistication issue may cut against" the plaintiff. ${ }^{306}$

The consumer behavior literature suggests that cognitive capacity increases non-monotonically with age - i.e., that as children mature into adults, they gain a greater processing capacity, which eventually diminishes with old age. ${ }^{307}$ But that phenomenon alone cannot support a general presumption that the child consumer is necessarily careless. In some cases, a child may be highly

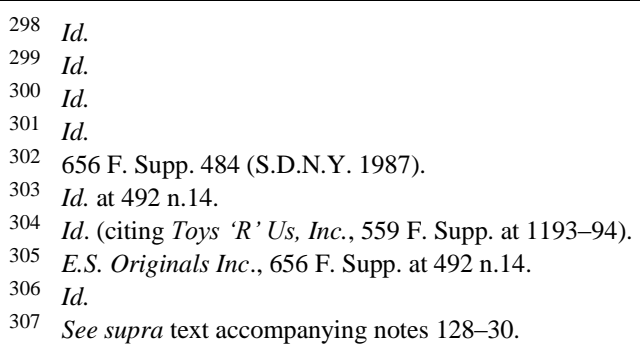


motivated to exercise a high level of care despite diminution in capacity. Our model also counsels, however, against embracing the opposite presumptionthat the child consumer is the one "most likely to insist on the advertised product and ... not likely to accept a substitute." ${ }^{\text {308 }}$ This may or may not be true, and depends (among other things) on whether perceived risk factors correlate with age. It seems plausible, for example, that younger consumers may sometimes be more susceptible to concerns about social risk - to the peer pressure associated with having the "right" brand of clothing, consumer electronics, or other products. Children may also be more prone to perceive financial risk to the extent their wealth is lower than their adult counterparts. Thus, younger consumers may possess diminished capacity for extended cognition, but in some circumstances they may be more highly motivated to perform the source-identification judgment with accuracy.

Consider the above-cited cases involving trading cards, magazines, and pop music records. ${ }^{309}$ These are relatively low-priced items, involving little financial risk. ${ }^{310}$ Perhaps more importantly, the trading card, magazine, and pop record cases arguably did not implicate any significant social risk on the part of the child consumer. In the trading card case, the court noted that the defendant's cards bearing photographs of world-famous cars were simply indistinguishable from the "cards licensed by Plaintiffs." 311 For the child consumer, the significance of that fact is that there is no social risk associated with being "caught" by one's peers in possession of a cheap knockoff of the original. As to the "King of Pop" record marketed by the defendant in the General Foods case, the plaintiff did not compete in the business of selling records (but rather sold only Pop Rocks candy), ${ }^{312}$ so again the social risk associated with owning a knockoff arguably was not implicated.

Contrast the child consumer in the Stride Rite case. In that case the court found that the plaintiff's "Zips" shoes had become "something of a status symbol among children aged two to eleven." court may well have been right to find that the target consumers were those "most likely to insist on the advertised product and . . not likely to accept a

\footnotetext{
308 E.S. Originals Inc., 656 F. Supp. at 491.

309 See supra notes 294-96 and accompanying text.

310 This conclusion may be mitigated somewhat by the fact that child consumers are generally less wealthy than adult purchasers - a consideration that suggests that children may perceive greater financial risk than adults would for similarly priced items.

311 Chrysler Corp. v. Newfield Publ'ns, Inc., 880 F. Supp. 504, 511 (E.D. Mich. 1995).

312 Gen. Foods Corp. v. Mellis, 203 U.S.P.Q. 261, 261-62 (S.D.N.Y. 1979).

313 E.S. Originals Inc., 656 F. Supp. at 492.
} 
substitute.",314 But these consumers" "sophistication" is not connected to age per se; it comes from the "status symbol" point, which translates into a high level of perceived social risk by young consumers. ${ }^{315}$

Ultimately, then, the results of many of the age cases are sustainable under the consumer behavior model, but the courts' rhetoric is overbroad. Instead of embracing a general presumption of carelessness (or sophistication) on the part of the child consumer, the courts should look carefully at the consumer's motivation and opportunity to exercise care. Where there are no substantial risk factors triggering enhanced motivation (as in the trading card, magazine, and pop music record cases), the child consumer's diminished capacity for cognition could be expected to produce a relatively careless purchase. In other cases, however, such as the clothing cases where social risk is a significant possibility, the child consumer's motivation may be sufficient to generate a high level of care. ${ }^{316}$

Indeed, where the parent is the actual buyer and the child is the end consumer, the child's diminished capacity may be practically irrelevant, as it is the parent (vicariously moved by the child's motivation) whose capacity is employed to effect the ultimate purchase. ${ }^{317}$ Thus, where the child consumer is sufficiently motivated to engage in a careful transaction, we may expect a "sophisticated" transaction regardless of the end-consumer's youth. This conclusion will hold so long as the child consumer has sufficient capacity to generate the "nagging . . . coercion" 318 necessary to persuade her parents to effect the transaction on her behalf.

314 Id. at 491 n. 14.

315 Another example is Original Appalachian Artworks, Inc. v. Blue Box Factory, 577 F. Supp. 625, 632 (S.D.N.Y. 1983). In that case, the plaintiff asserted an unfair competition claim against the defendant's knockoff of the plaintiff's Cabbage Patch Kids doll, and the court found a relatively high degree of consumer care. The court's analysis - that the parent's care in looking "for a label that clearly identifies the doll by name" is triggered by the knowledge "that the child will be bitterly disappointed by an imitation," id.- can easily be stated in social risk terms. If the child consumer fears being judged socially when her peers find her in possession of an imitation of the genuine article, there may be sufficient motivation for a careful purchase even where the ultimate consumer rates relatively low on the capacity scale.

316 An important caveat here is that it is perceived risk that triggers motivation, and that a relatively unwealthy child consumer may perceive greater financial risk in low-priced purchases than their adult counterparts.

317 The CABBAGE PATCH case illustrates this point. See Original Appalachian Artworks, Inc., 577 F. Supp. 625. As the court noted, it is the parent who will ultimately be the one who "looks [carefully] for a label that clearly identifies the doll by name," spurred on by the vicarious motivation "that the child will be bitterly disappointed by an imitation." Id. at 631 .

318 Toys 'R' Us, Inc. v. Canarsie Kiddie Shop, Inc., 559 F. Supp. 1189, 1199 (E.D.N.Y. 1983). 


\section{Gender}

In a handful of cases, the courts have posited that women are more careful consumers than men. This proposition has been proffered most often in cases involving perfume, ${ }^{319}$ skin care products, ${ }^{320}$ and apparel. ${ }^{321}$ In Nina Ricci, S.A.R.L. v. Gemcraft Ltd., ${ }^{322}$ for example, the Southern District of New York concluded that "[w]omen who use expensive perfumes are discriminating and sophisticated consumers" who "know their perfume" and are "discriminating enough to notice the difference of the aroma of [defendant's perfume] should they mistakenly use that product." 323 "Men who purchase expensive perfumes as gifts," by contrast, were deemed "somewhat less discriminating" and apt to "buy and run." 324 Because both women and men may be in the market for purchasing perfume, the Nina Ricci court found that the sophistication factor "weigh[ed] only slightly in defendant's favor.",325

A similar conclusion was advanced by the same court in Avon Shoe Co. v. David Crystal, Inc. ${ }^{326}$ Avon Shoe involved a defendant's use of the HAYMAKER mark on sportswear-a use challenged by the plaintiff, who owned the registration of the HAYMAKERS mark for women's casual shoes. ${ }^{327}$ Citing the Second Circuit's decision in Warner Bros. v. Jantzen,

319 See La Cibeles, Inc. v. Adipar, Ltd., 2000 WL 1253240, at *12 (S.D.N.Y. 2000) (holding that "women tend to be sophisticated purchasers of perfume") (quotations omitted); Giorgio Beverly Hills, Inc. v. Revlon Consumer Prods. Corp., 869 F. Supp. 176, 185 (S.D.N.Y. 1994) (declaring that "it has been acknowledged that women tend to be sophisticated purchasers of perfume"); Elizabeth Taylor Cosmetics Co. v. Annick Goutal, S.A.R.L., 673 F. Supp. 1238, 1246 (S.D.N.Y. 1987) (holding that because "there are really two groups of perfume consumers: women who buy the products for themselves and men who buy it as gifts for women[,]" there is some question as to sophistication because the female purchasers tend to be sophisticated while the male purchasers do not).

320 See Clinique Labs., Inc. v. Dep Corp., 945 F. Supp. 547, 556 (S.D.N.Y. 1996) ("The evidence shows that most consumers of skin care products are women who take care in deciding what products to use on their skin, particularly the skin on their faces .... Under these circumstances, sophistication of consumers usually militates against a finding of likelihood of confusion.").

321 See Kookai, S.A. v. Shabo, 950 F. Supp. 605, 609 (S.D.N.Y. 1997) (finding that young women buyers of wearing apparel may be "sophisticated" and exercise care in buying, but they "are not professional clothing purchasers and cannot be expected to have the same level of knowledge as professionals").

322612 F. Supp. 1520 (S.D.N.Y. 1985).

323 Id. at $1529-30$.

$324 I d$. at 1530.

325 Id.; see also Conopco, Inc. v. Cosmair, Inc., 49 F. Supp. 2d 242, 257 (S.D.N.Y. 1999) (finding that "purchasers of expensive perfumes from high-end department and specialty stores, who are often assisted by retail selling specialists and beauty advisors, ... are sophisticated and discriminating consumers").

326171 F. Supp. 293, 303 (S.D.N.Y. 1959).

327 Id. at 295-96. 
Inc., ${ }^{328}$ the Southern District asserted that "[t]he courts will take judicial notice of 'a certain degree of sophistication' of women purchasers., 329

Professor McCarthy characterizes these pronouncements as "an apparent bow to feminist superiority" and questions "the wisdom of such a sweeping judicial observation about relative sophisticated buying habits based on gender." ${ }^{\text {"330 }}$ There may be reason to be skeptical about the breadth of the courts' sweeping pronouncements, but the consumer behavior literature provides some support for the results (if not the generalizations) of the cases.

There is some support in the consumer behavior literature for the proposition that women may in fact be more careful consumers, ${ }^{331}$ and our model suggests some possible theoretical grounds for this conclusion. Women may tend to be more situationally involved in certain kinds of purchases, because they tend to perceive heightened levels of risk. They may tend to be more enduringly involved in certain purchase processes, and they may possess greater capability because of their relatively greater experience (to the extent culture or other factors put them in the role of buyer more frequently than their male counterparts).

We do not pretend to know whether or to what extent these generalizations are accurate. For present purposes, our point is only that these factors could provide a theoretical explanation for a consumer sophistication "gender gap." Returning again to the above-cited cases, it may be that women would be more careful consumers of perfume, skin care products, and apparel. ${ }^{332}$ This would be true if women are more situationally involved in such purchases (because, for example, they perceive greater social risk in such purchases than men would tend to perceive); if women are more enduringly involved in such

328 249 F.2d 353, 354 (2d Cir. 1957).

329 Avon Shoe, 171 F. Supp. at 303. In fact, the Warner Bros. case was not good authority for any sort of presumption of female superiority. The Second Circuit's decision in that case instead only adverted to a general level of sophistication among all consumers (male and female) — on the rationale that "[i]nsistent American advertising, whatever its faults, has surely induced a certain degree of sophistication and wariness in us all." Warner Bros., 249 F.2d at 354.

330 MCCARTHY, supra note 2, § 23:99. But see Bartow, supra note 10, at 778 (expressing the "Author's strong impressionistic reaction, provoked by exposure to numerous written opinions in the context of teaching courses in trademark law, . . . that judges will more readily find sufficient consumer confusion likely where the underlying products or services are female oriented in some manner").

331 Joan Meyers-Levy \& Brian Sternthal, Gender Differences in the Use of Message Cues and Judgments, 28 J. MARKETING RES. 84, 86 (1991) (evaluating data from two experiments, which suggests that the genders differ in how they make judgments; concluding that, in comparison with men, women have a lower threshold for elaborating on message cues and thus make greater use of such cues in judging products).

332 See supra notes 319-21. 
purchases (because they are more "in to" these products than most men); or if they are simply better at making the source-identification judgment (which they may be if they have greater experience in buying these items). For these reasons, there may be a basis for the courts' findings that women are more sophisticated consumers in these product categories.

\section{F. Conclusion}

The consumer behavior model provides an analytical framework for evaluating a wide range of considerations identified by the courts as relevant to the degree of consumer care. Under the light of our model, the courts can move beyond the rough, intuitive assertions that currently dominate judicial treatment of this issue and engage in a more theoretically sound evaluation. Although our model cannot quantify the expected impact of any particular risk factor or even dictate the relative weight to assign to factors that may point in different directions, it does provide a theoretical framework for understanding the relevance and qualitative impact of the above considerations on the degree of consumer care.

\section{THE CONSUMER BeHAVIOR MOdel as A CONSTRUCT FOR EVALUATING THE RELEVANCE AND RELATIVE WEIGHT OF CONSUMER SOPHISTICATION AND CARE}

The consumer behavior model also provides a basis for evaluating a number of the broader issues addressed by the case law described above. In the paragraphs below, we employ our model to analyze the case law regarding the relative weight to be assigned to the consumer sophistication factor in the likelihood of confusion calculus as well as the cases evaluating the significance of this factor in circumstances involving sponsorship confusion, post-sale confusion, and initial-interest confusion.

\section{A. Consumer Sophistication: A Trump Card or a Factor of Minimal Significance?}

On the question of the relative significance of the consumer sophistication factor, two apparently opposing positions have been staked out in the case law. The Fourth Circuit has assigned substantial - even controlling - weight to the degree of consumer sophistication. ${ }^{333}$ In the Fourth Circuit, the "relative

333 Sara Lee Corp. v. Kayser-Roth Corp., 81 F.3d 455, 467 (4th Cir. 1996). 
sophistication of the market may trump the presence or absence of any other factor." ${ }^{, 334}$ Thus, in Perini Corp. v. Perini Construction, Inc. ${ }^{335}$ the court held that "in a market with extremely sophisticated buyers, the likelihood of consumer confusion cannot be presumed on the basis of the similarity in trade name alone.",336

Although the junior and senior marks were essentially identical in their use of the PERINI name, and the parties sometimes competed for the same jobs in the construction business, the Perini court reversed summary judgment for the plaintiff, primarily on the ground that the consumer sophistication factor was potentially dispositive:

The district judge below erred because he made no inquiry into the sophistication of the ordinary consumer of construction servicesmost likely a highly trained procurement professional whose sensitivity is heightened by the responsibility of sensibly spending millions of dollars. Evidence introduced by Perini Construction casts considerable doubt on the district court's implicit assumption that construction services are procured on the basis of the name of the firm alone. ${ }^{337}$

The Perini court credited affidavits in the record, indicating that the multimillion dollar construction contracts that the parties competed for were unlikely to be awarded "simply on the basis of a similar name," and that the sophisticated bidders for such contracts " placed a strong emphasis on intimate knowledge of each and every one of the companies to which it awarded contracts." "338 In light of this evidence, the Fourth Circuit in Perini concluded that "the sophistication and expertise of the usual purchasers [could] preclude any likelihood of confusion among them stemming from the similarity of trade names." 339 Callmann's treatise on Unfair Competition expresses a similar view, positing that a high degree of consumer care is - sometimes - a "factor[] of greater significance than the trademarks used." ${ }^{\text {340 }}$

The Sixth Circuit has stated the opposite conclusion - that "[t]he effect of purchaser care, although relevant, will be less significant than ... the similarity

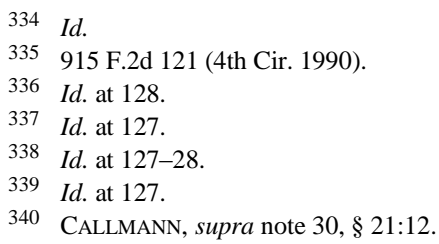


of the marks at issue." ${ }^{341}$ The Second Circuit's approach is similar. In Kiki Undies Corp. v. Promenade Hosiery Mills, Inc., ${ }^{342}$ the Second Circuit opined that "the import of this factor is small indeed," at least in cases where the junior and senior marks are "identical.",343

In the Kiki Undies case, the defendant had used the KIKI trademark on women's tights in close proximity with the plaintiff's use of the identical mark on pantyhose. ${ }^{344}$ Noting that the defendant had "put[] its tights in a transparent package, similar in size and shape to that of the plaintiff," the court found that "the marks used by plaintiff and defendant [we]re not only similar but identical." ${ }^{345}$ Under the circumstances, although "[t]he sophistication of the buyers [was] not documented" in evidence, the court found that the consumer sophistication factor was of minimal relevance "assum[ing] an average group of buyers." 346

A similar analysis was embraced by the Southern District of New York in Habitat Design Holdings Ltd. v. Habitat, Inc. ${ }^{347}$ In that case, the court considered the likelihood of confusion stemming from the junior use of the HABITAT trademark on furniture and lighting in conjunction with the senior use of the same mark on china and glassware. ${ }^{348}$ Although the court found that "the relative sophistication of purchasers of expensive furniture spans a broad spectrum," including "both discriminating and casual . . . buyers," it declined to give much weight to the consumer sophistication factor, stating that "[t]he Second Circuit has noted that the importance of this criterion is minimal where the marks in question are identical., 349

341 Daddy's Junky Music Stores, Inc. v. Big Daddy’s Family Music Ctr., 109 F.3d 275, 286 (6th Cir. 1997); see also Therma-Scan, Inc. v. Thermoscan, Inc., 295 F.3d 623, 638 (6th Cir. 2002) (suggesting that "the significance of the likely degree of purchaser care . . . decreases considerably" when there is a "high degree of similarity between" the parties' trademarks).

342411 F.2d 1097 (2d Cir. 1969).

343 Id. at 1101.

344 Id.

345 Id. at 1100.

346 Id. at 1101. The Second Circuit followed a similar approach in Omega Importing Corp. v. Petri-Kinen Camera Co., 451 F.2d 1190, 1195 (2d Cir. 1971), concluding that the competing use of the EXAKTA mark by both West German and East German manufacturers was likely to confuse even sophisticated consumers, and explaining that "purchaser inspection would be of doubtful value" where, "except for the reference to the place of manufacture, the names are identical."

347 436 F. Supp. 327, 331 (S.D.N.Y. 1977).

348 Id.

349 Id. at 332. 
Our model provides a basis for reconciling these apparently opposing positions. ${ }^{350}$ In some limited circumstances (such as in Perini), ${ }^{351}$ it may well be that a high degree of consumer sophistication will trump other factorsincluding the apparent identity of the parties' marks. In others (such as in Habitat Design), ${ }^{352}$ the "import of this factor" will be "small indeed." Ultimately, our model indicates that the relative impact of the consumer sophistication factor will depend on the nature and degree of motivation and ability for the consumer to exercise care under the circumstances.

Consumer care will have its anticipated effect of diminishing the likelihood of confusion if, and only if, the consumer's exercise of care can be expected to reveal a distinction between the senior and junior sources. That may not happen if, for example, the junior mark is identical to the senior one and the consumer lacks adequate motivation to pursue an inspection beyond a simple comparison of the junior and senior labels. Consider the Habitat Design case, where any supposed sophistication of purchasers of "expensive furniture" was deemed to be of "minimal" significance. ${ }^{354}$ Such a finding can be explained by our model if there is inadequate motivation for the exercise of consumer care that would extend beyond a mere comparison of the parties' facially identical trademarks. That is apparently the case under the Habitat Design facts, given that the two marks "appear[ed] almost identical" to each other when "printed in a magazine or typed on a purchase order," and any enhanced motivation (stemming from financial or social risk) seems unlikely to be sufficient to produce the further investigation necessary to dispel the apparent connection between the junior and senior marks. ${ }^{355}$

Indeed, and more fundamentally, our model suggests that there is an oversimplification in the case law's treatment of consumer care and sophistication.

350 Professor Beebe's empirical study finds that the consumer sophistication factor may have a statistically significant impact on a court's evaluation of the likelihood of consumer confusion, but that the impact of this factor appears to be least significant in the Second Circuit. Beebe, supra note 13, at 1612, 1642-43. These empirical findings are consistent with the doctrinal exposition above, which shows the Second Circuit's reluctance to give substantial weight to the sophistication factor. But Beebe's empirical study leaves unanswered the question of whether (and when) sophistication should be a significant factor in the likelihood of confusion analysis. We turn to that question below, at least at a theoretical level (leaving for future study the crucial empirical question of whether and to what extent consumer sophistication really does impact the likelihood of confusion).

351 Perini Corp. v. Perini Constr., Inc., 915 F.2d 121,128 (4th Cir. 1990).

352 Habitat Design Holdings Ltd., 436 F. Supp. at 331.

353 Kiki Undies Corp. v. Promenade Hosiery Mills, Inc., 411 F.2d 1097, 1101 (2d Cir. 1969).

354 Habitat Design Holdings Ltd., 436 F. Supp. at 331.

355 Id. at 322. 
The courts generally assert that a careful consumer is less likely to be confused as to source or sponsorship. ${ }^{356}$ But that conclusion follows only where the indicators of consumer care-motivation and ability - are likely to be directed at the source-identification judgment and not at something else. Since some highly motivated consumers may care mostly about price or some other consideration other than source, the so-called sophisticated consumer may not ultimately be one who is less likely to suffer source confusion.

Compare two "sophisticated" consumers of meat: one a professional buyer for a restaurant chain and the other a backyard barbeque aficionado. Both consumers may possess a similar quantum of motivation to expend cognitive resources in the purchase transaction, but the latter may be more likely to direct those resources toward the source-identification judgment. Some of the barbeque aficionado's motivation may stem from social risk-from a concern about judgments by her peers about the brand of meat she uses. That motivation is directly related to source-identification-since the very risk at issue depends on an accurate performance of the source-identification judgment (i.e., buying the "right" brand). Where, as with "sophistication" cued by perceived social risk, the consumer's motivation can be fulfilled only by cognitive efforts aimed at source-identification, the courts are on solid theoretical ground in inferring an inverse relationship between consumer care and confusion. ${ }^{357}$

The professional buyer's motivation is less likely to be related to source identification. Much of the motivation for the professional buyer will stem from perceived financial risk, since the restaurant chain's profits will depend on both the quality of the meat purchased and the price paid for it. If meat quality can be determined directly and without regard to source-e.g., by consideration of USDA meat grades - the professional buyer's motivation may be satisfied by cognitive efforts unrelated to the source-identification judgment. Thus, where the consumer's motivation is not directly related to source-identification, the inverse relationship between consumer care and confusion is more tenuous. ${ }^{358}$

356 See supra notes 24-29 and accompanying text.

357 See supra Part I.

358 As explained in greater detail in Part II, we do not mean to suggest that the connection is non-existent under these circumstances. It may well be that a consumer motivated by perceptions of financial risk will be motivated to some degree to perform the source-identification judgment, as where the consumer believes that brand identification is a useful shortcut for predicting quality or price. Comparing the two consumers above, however, the professional buyer seems less likely to rely on such a shortcut than the barbeque enthusiast. The key point, moreover, is that not all motivations for cognitive effort should be of equal relevance in the law. 
This does not mean that consumer sophistication can never trump a close facial similarity between two trademarks. Indeed, the Perini court's analysis is also defensible under our framework. ${ }^{359}$ Our model indicates that point-of-sale confusion will be dispelled if consumers are sufficiently motivated to move beyond a mere comparison of the parties' identical trademarks and investigate whether those same names really emanate from separate sources. It may be the rare case where consumer motivation will be that strong, but Perini may be just such a case. ${ }^{360}$ In Perini, consumer motivation was at its apex, since the relevant consumers were "highly trained procurement professional[s] whose sensitivity [was] heightened by the responsibility of sensibly spending millions of dollars." ${ }^{361}$ In such circumstances, we might expect point-of-purchase confusion to be dispelled by the careful investigation of these highly involved consumers - consumers who face financial risk associated with a high-stakes transaction, who possess enduring involvement in connection with their jobs, or who have an enhanced ability because of their training. Indeed, the evidence in the Perini case appeared to support such a conclusion, in establishing that "construction services [we]re [never] procured on the basis of the name of the firm alone," that bidders "placed a strong emphasis on intimate knowledge of each and every one of the companies to which [they] awarded contracts," and that "the investigation process [was] simply too detailed" to allow confusion of the two Perini entities in the bidding process. ${ }^{362}$

Thus, the consumer behavior model prescribes a course of moderation between the rhetorical extremes articulated in the case law. Consumer sophistication may be of "minimal" significance, or it may sometimes be a "trump" card; its value is dependent on whether there is sufficient motivation and ability to incite the degree of care necessary to dispel confusion between two apparently similar trademarks. Although the moderately motivated consumers in Habitat Design were unlikely to look beyond the facial identity of the HABITAT brand on the parties' furniture and glassware, ${ }^{363}$ the bidders for construction contracts in Perini possessed the sort of extraordinary motivation and opportunity necessary to distinguish Perini Corp. from Perini

\footnotetext{
Some highly motivated consumers will be more likely than others-even others with a similar "level" of motivation-to devote their cognitive efforts to the source-identification function. We leave for future evaluation the question of whether this insight may have broader implications for the case law in this field.

359 See Perini Corp. v. Perini Constr., Inc., 915 F.2d 121,128 (4th Cir. 1990).

360 Id.

361 Id. at 127.

362 Id. at $127-28$.

363 Habitat Design Holdings Ltd. v. Habitat, Inc., 436 F. Supp. 327, 331 (S.D.N.Y. 1977).
} 
Construction. ${ }^{364}$ Thus, sophistication could be said to be a trump card in cases like Perini, but it is of minimal significance in cases like Habitat Design.

\section{B. Consumer Sophistication and Sponsorship Confusion, Post-Sale Confusion, and Initial-Interest Confusion}

Our model also gives reason to suspect that consumer sophistication may not be as effective at dispelling confusion other than at the point of sale-e.g., sponsorship confusion, post-sale confusion, and initial-interest confusion. In King of the Mountain Sports, Inc. v. Chrysler Corp. ${ }^{365}$ the Tenth Circuit asserted that consumer care "rarely reduces the risk of sponsorship confusion."366 The Sixth Circuit has likewise suggested that "a purchaser who is extremely careful and knowledgeable" may "assume nonetheless that the seller is affiliated with . . . the other party." ${ }^{367}$

Our model lends theoretical support for these conclusions. If the relevant confusion is as to two independent sources, the exercise of a high degree of care could be expected to dispel it-in that further investigation could be expected to identify the existence of two separate entities. Thus, as a consumer's involvement increases, she may be more likely to ascertain that Perini Corp. is not the same entity as Perini Construction. ${ }^{368}$ But the consumer's investigation may not dispel confusion as to sponsorship. Even a highly involved consumer could still believe that Perini Construction is affiliated with or sponsored by Perini Corp., even after ascertaining that the two entities are separate.

Consider a variation on the Habitat Design case, in which the consumer is sufficiently motivated to determine that the maker of Habitat furniture is not the same entity as the maker of Habitat glassware. ${ }^{369}$ The sophistication

364 Perini, 915 F.2d at 128.

365185 F.3d 1084 (10th Cir. 1999).

366 Id. at 1092.

367 Daddy's Junky Music Stores v. Big Daddy's Music Ctr., 109 F.3d 275, 286 (6th Cir. 1997) (concluding that sophistication with respect to a musical instrument should not be expected to dispel confusion as to whether two music stores with similar names may nonetheless be affiliated); see also Champions Golf Club, Inc. v. The Champions Golf Club, Inc., 78 F.3d 1111, 1120-21 (6th Cir. 1996) (asserting that "[i]t is not particularly significant . . . that it is unlikely that any golfer would end up on the first tee at" one golf course "thinking he or she was on the first tee" at a similarly named golf course, and that "[t]he relevant question is whether a golfer, albeit sophisticated, would likely be confused about affiliation between the two clubs").

368 Perini, 915 F.2d at 128.

369 See Habitat Design Holdings Ltd. v. Habitat, Inc., 436 F. Supp. 327 (S.D.N.Y. 1977) (proposing a general hypothetical variation on the case throughout). 
necessary to come to that conclusion falls far short of that necessary to dispel any appearance of sponsorship or affiliation. In order to dispel that confusion, the consumer would have to achieve rather heroic heights of sophistication, in which she not only identifies the furniture maker as a separate entity but also proves the absence of any licensing or sponsorship agreements between them. ${ }^{370}$ That level of sophistication would be the rare case indeed. ${ }^{371}$

In fact, high levels of involvement might even be expected to exacerbate the likelihood of sponsorship confusion-particularly with respect to junior marks that are identical to the senior mark. An unauthorized sale of Habitat furniture might be most naturally connected (in a sponsorship or licensing sense) to the senior HABITAT mark by a consumer who is highly involvedsince the exercise of consumer care can only increase the perception of a connection between two disparate uses of the same trademark, and no amount of additional comparison of the two marks is likely to dispel it. ${ }^{372}$

The same conclusions hold with respect to post-sale confusion. The prototypical case of post-sale confusion involves the purchase of a knockoff of a famous, exclusive item (like a Rolex watch) by a buyer who knows she is getting an imitation. Two principal justifications have been offered for imposing liability under such circumstances: (1) some sales are diverted from the senior user to buyers whose purchase is based on the expectation that third parties will mistakenly assume that their knockoff is genuine; ${ }^{373}$ and (2) some

370 See, e.g., E. \& J. Gallo Winery v. Gallo Cattle Co., 967 F.2d 1280 (9th Cir. 1992); Nina Ricci, S.A.R.L., v. E.T.F. Enter., Inc., 889 F.2d 1070 (Fed. Cir. 1989); and John B. Stetson Co. v. Stephen L. Stetson Co., 85 F.2d 586 (2d Cir. 1936).

371 At the extreme, it is certainly conceivable that the most highly involved consumer could eventually determine the absence of any licensing or sponsorship agreement between the senior and junior entities. But the hypothetical consumer who would be involved to that degree is not only rare but she is also undoubtedly greatly outnumbered by those consumers who don't get quite to that level and whose likelihood of confusion as to sponsorship is only enhanced by her sophistication.

372 This is a point that we develop at some length in a forthcoming article, which presents a theoretical model and the results of an empirical survey to demonstrate that (a) high involvement may increase the likelihood of sponsorship confusion, particularly where (b) the market has already been subject to "brand extension." Eric D. DeRosia, Thomas R. Lee \& Glenn L. Christensen, Sophisticated but Confused: Brand Extension and Motivation as Factors Increasing the Likelihood of Source Confusion (unpublished manuscript, on file with authors).

373 See, e.g., Mastercrafters Clock \& Radio Co. v. Vacheron \& Constantin-Le Coultre Watches, Inc., 221 F.2d 464, 466 (2d Cir. 1955) (finding infringement of ATMOS clock mark on cheap imitation and explaining that "at least some customers would buy [the copier's] cheaper clock for the purpose of acquiring the prestige gained by displaying what many visitors at the customers' homes would regard as a prestigious article," and that the copier's "wrong thus consisted of the fact that such a visitor would be likely to assume that the clock was an Atmos clock"); MCCARTHY, supra note 2, § 23:7 (discussing cases and explaining that "[t]he damage to the senior user in such a case is that consumers could acquire the prestige value of the senior user's product 
potential consumers will attribute any negative experience with the knockoff to the senior trademark holder, resulting in a harm to the goodwill developed in the trademark and to a potential loss of future sales. ${ }^{374}$ Given these justifications, no amount of care or sophistication among point-of-sale purchasers will diminish the likelihood of cognizable confusion by third parties beyond the point of sale.

Consider a wholesaler of counterfeit Rolex watches who sells only to street peddlers who are highly motivated to expend cognitive resources in the sourceidentification judgment. These buyers are highly sophisticated and extremely unlikely to be confused about the source of the counterfeit watches they buy, but their sophistication is beside the point. Instead, in cases of cognizable post-sale confusion, the relevant sophistication is that of the third parties who may view the trademarked products in use. And such third parties are extremely unlikely to exercise the extended cognition necessary to perform the source-identification judgment with any accuracy, given that (1) there are unlikely to be any significant risk factors implicated in the context of a casual post-sale encounter with someone else's trademarked item; (2) there will often be time constraints and other situational limitations on the opportunity for extended cognition; and (3) the junior mark is often a bad-faith counterfeit carefully contrived so that only an expert would be able to distinguish it from an original.

Finally, our model also lends theoretical support to the judicial skepticism of the relevance of consumer sophistication in cases involving actionable "initial interest" confusion. ${ }^{375}$ The whole premise of the initial-interest cases is that a plaintiff's claim is not defeated by a showing that confusion will be dispelled by consumer care before the point of sale. ${ }^{376}$ Thus, where initial-

by buying the copier's cheap imitation," and that since the purchase depends on the expectation of third-party confusion "the senior user suffers a loss of sales diverted to the junior user, the same as if the actual buyer were confused").

374 See, e.g., Payless Shoesource, Inc. v. Reebok Int'1 Ltd., 998 F.2d 985, 989 (Fed. Cir. 1993); MCCARTHY, supra note 2, § 23:7 (discussing cases in which the purchaser knows that he or she is buying [an] imitation," but where "viewers who are prospective purchasers are confused, to the injury of the trademark owner").

375 See supra notes 43-46.

376 See MCCARTHY, supra note 2, §23:6 (explaining the initial-interest confusion principle-that "[i]nfringement can be based upon confusion that creates initial customer interest, even though no actual sale is finally completed as a result of the confusion"). 
interest confusion is legally cognizable, the expectation of a high level of care at later stages of the transaction is simply irrelevant. ${ }^{377}$

Indeed, as with sponsorship confusion, certain forms of consumer sophistication may only exacerbate the likelihood of initial-interest confusion. Consider the SecuraComm case discussed above. ${ }^{378}$ The fact that consumers of high-end security systems are likely to expend extensive cognitive resources at later stages of the purchase process is beside the point if their initial-interest confusion is itself actionable, ${ }^{379}$ and highly involved consumers are those most

377 The caveat-limiting this point to cases involving legally cognizable initial-interest confusion-is necessary to prevent the exception from swallowing the rule. Some instances of initial-interest confusion have been deemed too evanescent to merit a finding of infringement, as in cases where the parties' products are unrelated and sold in disparate marketing channels, and/or where there is no evidence of bad faith by the junior user. Checkpoint Sys., Inc. v. Check Point Software Techs., Inc., 269 F.3d 270, 299 (3d Cir. 2001); see also MCCARTHY, supra note 2, §23:6 (discussing cases on initial-interest confusion). In cases where there is no actionable initial-interest confusion, the consumer sophistication factor will play the usual role outlined in this Article. Indeed, it is worth noting that some forms of sophistication will be likely to diminish the likelihood of confusion at the point of sale-since some highly motivated consumers will direct their cognitive energy at discovering differences between two trademarks that appear similar at first glance.

For the same reason, it may be that the same "sophistication" that can exacerbate the likelihood of initial interest confusion will minimize the risk of the "bait-and-switch" problem that animates the doctrine of initial interest confusion. See Dorr-Oliver, Inc. v. Fluid-Quip, Inc., 94 F.3d 376, 382 (7th Cir. 1996) (describing initial interest confusion as the "'bait and switch' of producers"). If an involved consumer's motivation makes her unlikely to be satisfied with a counterfeit, her initial interest confusion may be not cognizable if she can be expected to hold out for the genuine article. See Original Appalachian Artworks, Inc. v. Blue Box Factory, 577 F. Supp. 625, 632 (S.D.N.Y. 1983) (asserting that children will be bitterly disappointed by an imitation).

378 See text accompanying note 46 (discussing SecuraComm Consulting, Inc. v. SecuraCom Inc., 984 F. Supp. 286 (D.N.J. 1997)).

379 Indeed, the legal notion of initial-interest confusion seems to correlate closely with another concept developed in the consumer psychology literature: "attention." See Celsi \& Olson, supra note 71, at 210-24 (presenting the results of a study designed to test several hypotheses concerning the effects of intrinsic and situational sources of personal relevance on felt involvement and on the amount of attention and comprehension effort, the focus of attention and comprehension processes, and the extent of cognitive elaboration during comprehension); Mackenzie, supra note 105, at 174-95 (presenting results of two experiments designed to test the hypothesis that the amount of attention drawn to an attribute by an advertisement mediates the effect of advertising on attribute importance). Attention is the consumer's choice of some stimulus (e.g., a product) from among the many stimuli in an environment (e.g., a retail setting), with the result that the consumer focuses cognitive effort upon that stimulus rather than the other stimuli. As is popularly understood, consumers' attention can be attracted by blinking lights and sudden noises. Steven Yantis, Control of Visual Attention, in AtTEnTION 223, 248 (Harold Pashler ed., 1998). Consumers' attention is also attracted to things in their environment that may fulfill a need and solve a problem, such as a needed product with a desirable brand. Rik Peters \& Michel Wedel, Goal Control of Attention to Advertising: The Yarbus Implication, 34 J. CONSUMER RES. 224, 224 (2007). As a result, consumers' attention can be attracted by a junior mark if it is similar enough to the senior mark to attract attention but dissimilar enough to be distinguished from the senior mark under the closer scrutiny described in this Article. The consumer psychology literature suggests that attention has a wide variety of antecedents. See HoYER \& MACINNIS, supra 
likely to be familiar with the senior SECURACOMM mark and thus to draw the misleading initial connection when they first hear of the junior mark SECURACOM. ${ }^{380}$ Thus, where sophistication is rooted in enduring involvement in or repeated exposure to a senior mark or product category, the sophisticated consumer may be the one most likely to develop an initial interest in a junior mark that at first glance appears similar. ${ }^{381}$

\section{CONCLUSION}

Trademark law is far too dependent on assumptions about consumer behavior to continue to evolve in ignorance of an entire body of scholarship devoted to that very subject. The law in this field has much to learn from the consumer behavior literature, and nowhere is that more evident than in the courts' ad hoc assessment of consumer care or sophistication. By making reference to the elements of the consumer behavior model, the courts can take significant steps beyond the stereotypes and often contradictory assertions that now dominate their treatment of this issue. The model can thus facilitate the sound development of the law in this area while also identifying course corrections like those identified above.

The consumer behavior model offers other insights that may help to shape the law in this area in ways not yet anticipated by the case law. One important, unexplored question is whether and to what extent the degree of consumer care may change over time and may be impacted by factors other than those identified by the courts - including, for example, the relative "strength" of the underlying trademark. Consumer care may tend to erode over time if perceived performance risk decreases as consumers become familiar with a new product line or brand and as the brand develops goodwill. If so, an initial finding of a high degree of consumer care may not stand as a reliable precedent over time, and a subsequent reassessment of such a finding may be necessary.

Consider the iPod brand. When the iPod was first introduced, various risk factors (primarily financial and performance risk) could be identified that would tend to heighten the motivation for increased consumer care. Over time,

\footnotetext{
note 100, at 80-83. We leave for another day - and perhaps a subsequent article - the analysis of the law's treatment of initial-interest confusion in light of the consumer behavior model of "attention."

380 See SecuraComm Consulting, Inc., 984 F. Supp. at 299.

381 See, e.g., Lois Sportswear, U.S.A. v. Levi Strauss \& Co., 799 F.2d 867, 875 (2d Cir. 1986) (concluding that "the sophisticated buyer is more likely to be affected by the sight of [the famous Levi's] stitching pattern on [the junior user's] jeans").
} 
however, those risk factors may tend to diminish in importance, not only as the price of a new electronic device falls, but also as consumers become more familiar with the brand and iPod gains strength and consumer goodwill. As that happens, the motivation for consumer care may diminish. If so, the model suggests an inherent danger in according too much significance to the expected degree of sophistication.

The danger is something of a vicious cycle: If courts limit the breathing room afforded to the iPod brand on the basis of a finding of a high level of consumer sophistication, competitors will come relatively closer to that brand (with variations on "Pod" or "i" in portable music players and accessories ${ }^{382}$ ). And while that is happening, consumers may tend to become less careful over time, such that the courts' initial finding of a high level of consumer care will aggravate the likelihood of confusion among the now less "sophisticated" consumers.

On this and many other issues, the consumer behavior model developed here should facilitate a more sound evolution of the trademark law. If courts will tap into the substantial insights offered in the above-cited literature, the courts can begin a move away from the ad hoc stereotypes that have too long dominated the case law.

382 See Shaun Nichols, Apple Cracks Down on Use of the Word 'Pod,' (Sept. 26, 2006), http://www. vnunet.com/vnunet/news/2164984/apple-goes-pod-makers (reporting that Apple is asserting infringement claims against the "myPodder" download service). 